Investing in Schooling in Chile:

The Role of Information

about Financial Aid for Higher Education

by

Taryn Dinkelman, Princeton University

Claudia Martínez A., Universidad de Chile

CEPS Working Paper No. 216

February 2011 


\section{Investing in schooling in Chile: The role of information about financial aid for higher education}

\author{
Taryn Dinkelman \\ Princeton University, BREAD and CEPR \\ tdinkelm@princeton.edu
}

\author{
Claudia Martínez A. ${ }^{1}$ \\ Universidad de Chile \\ cmartineza@econ.uchile.cl
}

February 14, 2011

Recent economic research shows that imperfect information about Mincer returns to education (in developing countries) or about financial aid (in the US) may undermine investments in schooling and exacerbate inequalities in access to education. We extend this literature by presenting the results of an experiment that provided children and a subset of their parents with specific information about financial aid for higher education, and measured the impact on effort in primary school. We developed a DVD information program and randomly assigned a sample of Chilean $8^{\text {th }}$ graders in poor urban schools to information treatment and control groups. Half of the treatment group watched the DVD at school (Student group) and the other half received a copy of the program to watch at home (Family group). Using survey and matched administrative data to measure outcomes three to six months post-intervention, we show that knowledge of financial aid sources improves in treated schools and school-reported absenteeism falls by $14 \%$. These responses appear to be driven by students with higher baseline grades; yet we find no significant effects on $8^{\text {th }}$ Grade scores or $9^{\text {th }}$ Grade enrolment for any students. While parents in the Family treatment group score significantly higher on tests of information related to DVD content, watching the DVD at home is no more effective at changing effort than watching at school, at least for high ability students likely to select in to watching the DVD. Our results suggest that Chile falls somewhere between developing and developed countries: exposure to information about financial aid for post-secondary schooling significantly affects student knowledge and absenteeism, but is insufficient for improving other educational outcomes.

JEL codes: $D 80,120,012$

\footnotetext{
${ }^{1}$ Funding for this project was provided by the Inter-American Development Bank, the Center for Economic Policy Studies at Princeton University and PEP-NET (the Poverty and Economic Policy Research Network). We thank Claudia Peirano and her team, especially Valentina Rivera, Patricia Reyes and Ilana Nussbaum, at the Centro de Microdatos at the Universidad de Chile for their tireless work and dedication in implementation of the project; Ana María Baeza and Paola Leiva at the Ministry of Education, Chile, for their assistance with the administrative data used in the paper; and Alberto Chong (IDB) for his continuous support of the study. We thank Nancy Qian, Tomas Rau, Sam Schulhofer-Wohl, Dean Yang and seminar participants at the Harris School of Public Policy, Princeton, MIT, Yale and the Rimini Conference in Economics and Finance (2010) for useful comments. Claudia Martínez A. acknowledges research support from the Iniciativa Cientifica Milenio to Centro de Microdatos, Project P07S-023-F.
} 
Broadening access to higher education is an important issue in many countries concerned with economic inequality and intergenerational income mobility. Children from poor backgrounds in middle- and upperincome countries do not advance in large numbers to post-secondary schooling, despite the fact that wage returns to higher education are large and educational aspirations among the poor are typically high. ${ }^{2}$ Credit constraints provide one plausible reason for this unequal access, and an established body of work largely based on US evidence has shown that providing financial aid for college can substantially raise enrollment and attainment for some types of students. ${ }^{3}$ However, recent work in less developed countries suggests that credit constraints may not be the most immediate obstacle to getting more education (Nguyen 2008, Jensen 2010). The starting point for this work is that before families can devise strategies to invest optimally in education, they must correctly value the benefits and costs of higher education. In many contexts, imperfect information about some aspect of the benefits or costs of higher education may present the first barrier to getting poor students into post-secondary schooling.

In Chile, where our study takes place, enrollment in and attainment of tertiary education is strongly correlated with family socioeconomic status. Although $18 \%$ of Chilean young adults aged 25-34 have completed some form of tertiary education (about the same percent as in Mexico), most of these graduates come from the upper income deciles in the country: In 2006, only $12.7 \%$ of $18-25$ year olds from the lowest income decile were enrolled in tertiary education, compared to $53.3 \%$ of the top income decile (CASEN, 2006). This unequal access and attainment stand in stark contrast to the universal primary school enrollment and massive increases in secondary schooling that have been achieved in that country in the past two decades. Several recent expansions in the supply of public financial aid for post-secondary schooling are partly aimed at addressing this inequality, but large changes in access at the lower end of the income distribution have not been realized.

Against this backdrop we ask: does a particular source of imperfect information about net returns to higher education -how to go about financing tuition -- lead students from poor backgrounds to underinvest in schooling early on in their school careers? We address this question by randomizing exposure to information about public and private financial aid for post-secondary schooling in a sample of poor urban $8^{\text {th }}$ Graders in Chile. The information is provided in a short DVD program we developed called "Open the

\footnotetext{
${ }^{2}$ Psacharopolous $(1985,1994)$ reviews the literature on returns to different levels of education. Although returns are everywhere highest for primary school, returns to higher education are still on the order of $20 \%$ in Latin America and even higher in poorer parts of the world. Attanasio and Kauffman (2009) and Chiapa et al (2010) describeeducational expectations in Mexico, Jacob and Wilder (2010) do so for the US. For Chile, data from the 2004 SIMCE national exam indicates that between 50 and $70 \%$ of students and their parents in the lowest two income quintiles expect some post-secondary education for themselves.

${ }^{3}$ See Angrist (1993), Dynarski (2002 and 2003) and Bound and Turner (2002) for US evidence. Using a structural model, Kauffman (2008) shows that poor Mexican students with high expected market returns to education underinvest in higher education due to credit constraints.
} 
Box" ("Abre la Caja”), in which young adults from similarly poor backgrounds discuss their postsecondary school trajectories in colleges and vocational schools. Through these stories, students learn about recently expanded public financial aid (scholarships and loans) for post-secondary study and are given specific details about how performance in school affects eligibility for this aid. Since qualifying for financial aid is a critical part of getting a higher degree for these poor students ${ }^{4}$, and preparation for eligibility starts much earlier than $12^{\text {th }}$ Grade, we interpret exposure to the DVD as providing students with a better understanding of the education production function and study their responses to this new knowledge.

The information is provided to two treatment groups of schools: in the Student treatment group, all students watch the DVD at school while in the Family treatment group each student is given a personal copy of the DVD program to watch at home with their families. ${ }^{5}$ The intervention was designed to shed light on (i) how important imperfect financial aid information is for behavior four years before students apply to higher education (ii) which types of students are most affected by this financial aid information and (iii) whether parental involvement in learning about this aspect of the costs of higher education has an additional impact on outcomes. ${ }^{6}$ In exploring these three questions, we learn not only about whether this particular intervention works, but also add to the literature on the role of that lack of information plays in affecting educational investment decisions more generally.

To evaluate the impact of exposure to new financial aid information, we collected rich survey data on higher education expectations and plans for financing further studies from over 6,000 students and their parents at baseline in July and August 2009 before applying the intervention in the Student and Family treatment schools. At a three month follow-up, we tested everyone for recall of specific information presented in "Abre la Caja" and collected school-reported absenteeism, one measure of effort in school. To flesh out the picture of how learning about financial aid resources affects educational investment decisions, we merged all of our survey data with administrative data on additional outcomes reflecting effort in school: school grades at the end of primary school, national exam scores in Grade 8 and school choice in Grade 9.

\footnotetext{
${ }^{4}$ Recent work by Meneses and Blanco (2010), and Solis (2010) indicates that actually being awarded financial aid for college in Chile massively increases the probability of enrollment among poorer students: on the order of 30\% increases in enrollment. These results, based on IV and RD research designs respectively, indicate the presence of substantial credit constraints for poor families.

${ }^{5}$ The research design implies that not all students and parents in the Family group will watch the DVD, which generates selection into who receives the information. The possibility of using parent-teacher meetings to provide the information to parents at schools was ruled out because of low attendance at similar meetings in our sample.

${ }^{6}$ Several strands of research in economics suggest or take as a starting point that adolescents may not be sufficiently forward-looking to incur the immediate effort costs associated with certain investments (Gruber 2001, Fryer 2010); one implication of this is that child and parent should be treated as separate agents with conflicting preferences in analyzing the school investment decision (for examples, see Kalenkoski 2007, Berry 2009, Lundberg et al 2009).
} 
Our analysis proceeds in two parts. In the first part, we estimate Intent to Treat effects for the Any Information treatment. We compare follow-up survey responses on financial aid information and educational expectations and administrative data on absenteeism, $8^{\text {th }}$ Grade scores and $9^{\text {th }}$ Grade enrollment for all students exposed to the DVD with control group student outcomes. As we show in a simple model of imperfect information about the education production process, it is ambiguous how or which students will respond most to the new information. Therefore, we explore differences in responses across high and low ability students using within-school variation in baseline student ability (grades in Grade 7).

Our estimates of the impact of exposure to "Abre la Caja" indicate that student information about financial aid options (particularly loans) for post-secondary study in Chile improved, and that this exposure shifted education expectations and improved some aspects of school behavior, although differentially for students of different baseline ability. Students in the information treatment groups are 4.6 percentage points more likely than students in the control group to report they will finance postsecondary studies using loan finance and score 5.5 percent higher on a test of financial aid information learned from the DVD. Students with higher baseline grades (our measure of observed ability) remember more information from the DVD, remember more relevant information (i.e. about scholarships and loans) and are more likely to expect to attend college after high school. Students with lower scores in comparison report smaller increases in rates of loan finance and are more likely to expect to study at a vocational school at follow-up, suggesting that the DVD may have led to sorting of students' education expectations.

The effects of exposure to "Abre la Caja" on school investments and outcomes three months after baseline are mixed. Absenteeism prevalence in the month before follow-up declines by $14 \%$ and absenteeism rates fall by a significant 0.08 standard deviations after exposure. Although we do not have the precision to detect smaller heterogeneous effects by ability, the pattern of coefficients is suggestive: students with medium and high grades at baseline appear to drive this absenteeism effect. The size of these absenteeism responses is comparable to the range of effects from other studies using different interventions to affect school behaviors: providing students in rural Madagascar with returns to education information (Nguyen 2008), the effects of providing deworming medication to Kenyan students (Kremer and Miguel 2004) and the effects of deworming and providing iron supplementation among Indian students (Bobonis et al 2006). Despite these absenteeism effects, our rich administrative data reveals no significant impacts on other margins of educational investment choices that are likely more difficult to change: grades at the end of $8^{\text {th }}$ Grade and choice of high school to attend. Given that the size of our 
absenteeism effect (on the intensive margin) is equivalent to an additional 2.5 days of school attendance over the school year, this is not surprising.

In the second part of our analysis we use the variation in how the information was presented in the Student and Family groups to consider the role that parental involvement may have in enhancing the size of these treatment effects. A comparison of outcomes across these treatment group assignments is complicated by two facts: differential compliance with watching the DVD in each group and the presence of treatment effect heterogeneity related to observable ability. We develop a novel method for making this comparison for the students who are likely to select into watching the DVD: we combine an IV procedure that instruments for watching the DVD within the Family group with a reweighting (RW) procedure that adjusts observations in the Student treatment to make them observationally similar to compliers in the Family treatment. This procedure enables us to compare effects for individuals similar to the compliers of the Family treatment.

In no case where we combine the IV and RW procedures can we reject the null that the two ways of presenting "Abre la Caja" have equivalent effects on behavioral outcomes. Even though parents in the Family treatment do learn significantly more about financial aid rules than parents in the Student treatment group, the impact of watching the DVD on behavior is not different across these two treatment groups, for the set of higher ability students who are likely to watch the DVD on their own. Given the limitations of our research design, we cannot say anything about how students of lower ability may be differently affected by parent involvement. However, the higher observed ability students are likely to be more relevant for policies related to expanding access to higher education

Our paper differs in several ways from the recent work that addresses information gaps related to the net returns to education for students in developing countries ${ }^{7}$ and from work showing that assistance with the financial aid application process improves access to higher education. ${ }^{8}$ We provide information to students and their families on how effort in school can prepare the student to meet eligibility criteria later on. Rather than informing students about wages associated with different levels of education and

\footnotetext{
${ }^{7}$ Jensen (2010) tests the impact of providing information on the Mincer returns to different levels of education on educational attainment to $8^{\text {th }}$ Graders in rural Dominican Republic (DR); Nguyen (2008) performs a similar test providing information on wages associated with different levels of education to parents of $3^{\text {rd }}$ Graders in rural Madagascar, with or without role models. Both randomized experiments find large positive effects of providing this information on school investments as measured by school attendance (3.5\% reduction in absenteeism in Madagascar), performance on tests ( 0.2 standard deviations in Madagascar), future school enrollment ( $7 \%$ higher in the DR the year after) and total educational attainment ( 0.2 years more in the DR).

${ }^{8}$ Field experiments in the US (Bettinger, Long, Oreopoulos and Sanbonmatsu 2009, Sacerdote and Carrell 2010) provide high school graduates and/or parents with information about and assistance with college financial aid applications close to the time of high school graduation. Bettinger et al (2009) find large increases in rates of college application and enrollment in among families who were assisted with completing complex financial aid forms.
} 
expecting students to figure out how to reach these higher levels of education, the DVD explains rules for eligibility and the importance of effort in high school for qualifying for this financial aid four years before the application process begins. We discuss how this leads to ambiguous predictions about effort responses in a simple model of effort choice. We also do not focus on how the financial aid information matters differently for families from different socio-economic backgrounds since all of the families in our sample are from poor backgrounds. Our intervention provides information that can help loosen credit constraints for all of these families later on, and so we focus on exploring how the marginal students are (i.e. who responds the most to this intervention). Finally, rather than considering the impact of information provided to parents alone, or to children alone, we test whether the information treatment effects are larger when parents in addition to children learn this new financial aid information. To our knowledge, this is one of the first studies to test whether parent learning about the education production function interacts with adolescent learning about this process to affect the size of the treatment response in a randomized experiment setting. ${ }^{9}$

The results of our analyses contribute to a growing literature indicating that information asymmetries and the costs of obtaining and processing information may severely distort education investments for children from poor families. We extend this literature by showing that information about financial aid availability and eligibility is differentially retained by students of different ability. We also find that even though providing financial aid information early on in a student's career can improve knowledge, shift expectations and reduce absenteeism, the type of information we provide is not sufficient for changing educational investments that are likely to have longer-run effects on post-secondary schooling: school grades and enrollment in a college-preparatory high school. In this respect, our results fall somewhere in between the results for developing countries (where providing different types of information has large effects on educational behaviors) and developed countries (where information alone seems to have little effect on behaviors). ${ }^{10}$ Perhaps the most surprising result of our study is that parent involvement in learning about financial aid opportunities does not have any additional impact on the education plans and school outcomes for students with high observed ability.

\footnotetext{
${ }^{9}$ Few papers step away from a unitary model of decision-making about educational investments to test whether parents or students are the more important agents in determining effort choice outcomes. Berry (2009) is an exception; he uses a field experiment to test for whether the identity (parent or child) of the recipient of a cash incentive matters for the effects of a learning incentive scheme in India. Using non-experimental methods, Attanasio and Kauffman (2009) show that mothers' and adolescents' expectations are predictive of the high school attendance decision while for college attendance choices, only adolescent expectations matter. Giustinelli (2010) also uses a structural model and survey data from Italian students to test whether child or parent beliefs and preferences over future outcomes are more important in determining school curriculum choice.

${ }^{10}$ This is in line with the results of field experiments in the US (Bettinger et al 2009) that show zero impacts of providing financial aid information only on college application rates, college enrollment or financial aid receipts.
} 
The paper begins by outlining relevant details of the Chilean education system and describing the intervention: sample selection, randomization and the characteristics of the information treatment. We discuss theoretical considerations in understanding student responses to this information exposure and then outline the empirical strategy, including how we deal with comparing the Student and Family treatments where there is selection into who watches the DVD in the Family treatment group. We define parameters of interest and then present the estimated effects of providing financial aid information on student information, expectations and behaviors for all students, and for students with different baseline grades. Finally, we present the results comparing the Student and Family effects and summarize what we learn in the conclusion.

\section{Background: Chile's education system}

Chile is the leading example of a country with a national education "market". The school voucher system introduced there in 1981 was designed to incentivize school quality improvements in response to demanddriven enrollment. This system has been the focus of several studies related to school outcomes and school choice. ${ }^{11}$ Since these papers fully describe primary and secondary education in Chile, we only describe aspects of the education system relevant for our study.

Chilean children start school at age six and must complete eight years of primary education and four years of secondary education. During their school careers, students and their parents face several important choices about educational investments: they must choose how hard to work in school, how much to attend, and in which schools to enroll. The choice about which high school to attend is generally made in Grade 8. Given the voucher system, students can, in theory, move between two types of publicly-funded schools: free municipal (public) schools and private, voucher-subsidized schools that may charge tuition. ${ }^{12}$ About $70 \%$ of the students in our sample are in municipal schools and the rest are in private subsidized schools. ${ }^{13}$ Students also choose whether to attend high schools that offer preparation for postsecondary studies (humanistic-scientific high schools) or those that offer vocational training which generally terminates in a $12^{\text {th }}$ Grade level of education.

Post-secondary vocational education is provided by Technical Training Centres (Centros de Formación Técnica or CFTs, two years of study) and at Professional Institutes (Institutos Profesionales or IPs, four

\footnotetext{
${ }^{11}$ Urquiola and Verhoogen (2009) examine the role of parental sorting across schools in affecting class size and class composition; Hsieh and Urquiola (2006) and Bravo, Mukhopadhyay and Todd (2010) examine the impact of the school voucher system on schooling and labor market outcomes. Mizala and Urquiola (2007) find little evidence that public school quality classifications affect enrollment, tuition or socioeconomic composition of schools.

${ }^{12}$ If public schools are selective in admissions, as some suggest, opportunities for students to move across schools may be limited (Gallego and Hernando 2009).

${ }^{13}$ Students may also opt out of the publicly-funded system to attend private unsubsidized secondary schools that typically charge high fees.
} 
years of study) and standard college degrees are attained at traditional Universities (five years of study). ${ }^{14}$ Tuition costs are high at all of these institutions: for households in the lowest decile of household income, one year of public university tuition was $141 \%$ of annual income in 2003; a year of technical college tuition was $89 \%$ of annual income. Good high school grades (Grades 9-12) and high scores on the college readiness exam, the PSU (Prueba de Selección Universitaria, like the SATs), are important not just for being accepted into all three institutions, but also to be eligible for financial aid.

Recently, financial aid programs for post-secondary education have expanded. Publicly-provided scholarships increased from USD 40 million in 2000 to USD 173 million in 2007 (OECD, 2009) and in 2006, the government expanded the public loan program to include coverage of post-secondary technical education in addition to traditional colleges. These recent, large expansions in financial aid support have created a range of new options for scholarships and loans for tertiary education (partial or full coverage, covering fees or food or transport or all costs). In our search, we found 11 types of public scholarships, four types of loans, as well as scholarships funded by private universities and donors.

Each scholarship and loan program has a different set of requirements -- all requiring good high school grades and many emphasizing good PSU performance, with different PSU cut-offs. ${ }^{15}$ Unfortunately, students from poor backgrounds and those attending free municipal schools are least likely to pass the PSU or earn the types of grades in Grade 9-12 that would make them eligible for this financial aid (OECD report 2009). Moreover, it is difficult for these students to easily find the relevant information required to help them prepare for higher education. Over half of the mothers of students in our sample have not completed high school and the several guidance counselors that we interviewed before our survey seemed not to know about most of these financial aid opportunities. This information gap about financial aid for post-secondary schooling is something that our intervention seeks to address.

\section{Experimental design}

The intervention provides students with information about how effort and good grades in school open up opportunities later on for further study, primarily by making it possible to apply for scholarships and government loans. Since high school performance is critical for financial aid eligibility and college admission in Chile, and because over $60 \%$ of Chilean students must choose a high school and a specific type of study at the end of $8^{\text {th }}$ Grade, we designed our intervention to target children four years before the

\footnotetext{
${ }^{14}$ In 2007, 660,000 young adults were enrolled in tertiary education: 68\% in college, $20 \%$ in IP and 12\% in CFT. It is estimated that approximately $13.8 \%$ of enrolled students have some type of scholarship, and $26.4 \%$ pay their studies with loans (OECD 2009).

${ }^{15}$ What we estimate in this paper is the effect of providing students with information about new sources of financial aid and the associated eligibility rules. If this information is likely to eventually filter out to all students then our intervention achieves a speeding-up of this dissemination process.
} 
relevant time for college and technical school applications.

We developed and produced a 15 minute DVD entitled "Open the Box" ("Abre la Caja") that collected together the tertiary education experiences of 13 adults ( 5 women and 8 men; 9 professional and 4 technical careers) who grew up in poor families in urban Chile. In the program, each person talks about how, by working hard at school and becoming eligible for financial aid, they were able to finance postsecondary education at traditional colleges or vocational schools. Their studies enabled them to become (among other things) civil engineers, graphic designers, chefs, social workers, lawyers and TV commentators. These life stories informed students about the existence of academic scholarships and student loans for further study and provided specific details on relevant high school grade cutoffs and PSU cutoffs for scholarship and loan eligibility. "Abre la Caja” standardizes these messages, which improves the fidelity of the treatment implementation. ${ }^{16}$

The study takes place in 226 schools in the lowest two income quintiles (defined by government administrative records) in Metropolitan Chile. We stratified the sample on school-averaged Grade 8 SIMCE scores from 2007 (SIMCE is a national annual test that is used to provide parents with one signal of school quality), and then randomly assigned schools to groups: 56 schools were randomly assigned to the Student information treatment (group A), 56 schools to the Family information treatment (group B), and the remaining 114 schools to the control group. Treatment was randomized at the school level to avoid information spillovers at the grade-level. More details about the recruitment process and application of the study are contained in Appendix A.

The baseline survey and intervention were conducted in late July and early August 2009. All students were given a baseline student questionnaire (self-responded, in class), and each child in every school also took home a parent questionnaire and was asked to return it to school a week later, at which time our enumerators collected these surveys. To incentivize return of the survey, we ran a lottery in which students who returned their parent surveys had the chance to win a computer. Since we were concerned with the potential selection problem of the returned parent questionnaire, we randomly assigned (at the school-level) the number of time the enumerators contacted and visited the school to pick up parent questionnaires (one, two or three times). ${ }^{17}$ After answering the baseline questionnaire, students in the treatment groups received the information provided in the DVD: Students in the Student group were shown "Abre la Caja" and students in the Family group were given their own copy of the DVD to take home and watch with their parents. No teachers were present in the classroom during our visit.

\footnotetext{
${ }^{16}$ Another nice feature of providing the information in the form of a DVD is that it is easily and cheaply scalable to more schools, in contrast to having role model-type speakers provide this information to students.

${ }^{17}$ This follows a solution to selected survey non-response suggested in Dinardo, McCrary and Sanbonmatsu (2006).
} 
At follow-up in November and December 2009, we revisited all schools and administered a selfresponded student questionnaire, with many of the same questions as in the baseline. ${ }^{18} \mathrm{We}$ asked students to take home another parent questionnaire and return it the following week, again for the chance to win a computer. At this time, we also collected school records on absenteeism for Grade 8 students for the whole year, up to the date of the follow-up visit. Schools were not expecting us to collect this information, and so it is unlikely that they could have retrospectively tampered with these administrative records. Only one school refused to participate in the follow-up, leaving us with follow-up data for 225 schools.

After our follow-up, we obtained administrative data from the Ministry of Education on student outcomes at the end of Grade 8 (reported at the school-level), student scores on the 2008 SIMCE exam, the outcome of Grade 8 (pass/fail/withdraw) and the school in which the student is enrolled in 2009. We matched all of our survey data with the administrative data using the national identification number and discuss match rates in the data description section below. Having a rich survey dataset along with the administrative data allows us to construct a comprehensive picture of how information sets, expectations, school behaviors and outcomes may have been affected by exposure to "Abre le Caja".

\section{Theoretical considerations}

In the standard human capital framework (Becker 1967, Card 1999), students choose an optimal level of schooling by balancing expected returns in the labor market with the costs of obtaining more education. Standard explanations for why students do not advance to higher levels of schooling are therefore related to credit constraints, low Mincer returns to more education or, in recent work (Jensen 2010, Nguyen 2008), uncertainty about these Mincer returns. We are interested in a fourth possible barrier to higher education: uncertainty about the production function for schooling. ${ }^{19}$ If students do not know the true mapping from effort in school to higher education, then optimal effort choices and eventual attainment depend on beliefs about how effort "produces" schooling.

It is worthwhile considering how students might respond to the information in "Abre la Caja" in such a world. Students who watch the DVD receive a new, standardized signal about how effort translates into more schooling: for example, they learn that scoring an average of 5.5 in high school is one component of scholarship eligibility, as is writing the PSU. A simple, stylized model of effort choice (adapted from Nguyen 2008 and Card 1999) can show that effort may increase or decrease in response, depending on

\footnotetext{
${ }^{18}$ Parental response rates are not statistically different across treatment and control groups; $75 \%$ of parents returned surveys to school at baseline; $58 \%$ returned surveys at follow-up. See Table 1.

${ }^{19}$ This is related to Fryer's (2010) point that students may not know how to "produce" educational outputs from inputs. In such a situation, incentivizing students based on educational output measures may be ineffective.
} 
initial beliefs about the parameters of the production function for schooling. This model is not intended to be general and is used here only to highlight that the direction of effort response to new information about financial aid is ambiguous.

Let student $i$ face a convex cost of effort function $c\left(e_{i}\right)$ and earn labor market returns to effort via a schooling production function $\left(\log y_{i}\left(e_{i}\right)=\beta_{i} S_{i}\left(e_{i}\right)\right)$, where $\beta_{i}$ captures the known Mincer returns to schooling for student $i$ and where, for simplicity, we assume log earnings are a deterministic function of schooling. Suppose the production function for schooling is $S_{i}\left(e_{i}\right)=A_{i} e^{\alpha}$. Student effort is the only input and there are positive and diminishing marginal returns to effort $(\alpha<1)$. Assume that students do not know the true average productivity shifter, $A^{*}$. Instead, they hold beliefs over this shifter $A_{i} \sim N\left(\underline{A}, \sigma_{\underline{A}}{ }^{2}\right)$ and choose effort to maximize expected utility given their distribution of priors:

$$
\max _{e_{i}} E\left[\beta_{i} S_{i}\left(e_{i}\right)\right]-c\left(e_{i}\right)
$$

The first order condition implies $\beta_{i} \alpha e_{i}^{(\alpha-1)} E\left[A_{i}\right]=c^{\prime}\left(e_{i}\right)$, meaning that $e^{*}$ is chosen to satisfy $\beta_{i} \alpha e_{i}^{(\alpha-1)} \underline{A}=$ $c_{i}{ }^{\prime}\left(e_{i}\right)$. Optimal effort in school depends on the shape of the distribution of beliefs about the average productivity parameter, the actual return to schooling (known to the student) and the marginal cost of effort. We might think of students with $\underline{A}<A^{*}$ as being pessimistic about their chances of obtaining more schooling at any effort level. These students underinvest in effort (and hence schooling). Students who are optimistic about how much extra schooling their effort "buys" $\left(\underline{A}>A^{*}\right)$ will overinvest in effort. ${ }^{20}$

We assume that the DVD provides students with the true average productivity parameter, $A$ * (i.e. we provide students with the "rules" about financial aid availability). ${ }^{21}$ Student should update their beliefs about how effort translates into more schooling, and indeed, we show in our empirical work that exposure to the DVD does improve student knowledge of the financial aid process. As these beliefs over $A_{i} \operatorname{shift} \underline{A}$ towards $A^{*}$, the first order condition implies that effort will adjust to bring the expected marginal return to effort back in line with the marginal cost of effort. Pessimistic students $\left(\underline{A}<A^{*}\right)$ should increase effort as they learn that a given level of effort now 'buys' them more schooling, through access to loan and scholarship programs (and vice versa for students with $\underline{A}>A^{*}$ ). In our empirical work, we find that no-one

\footnotetext{
${ }^{20}$ What we describe as uncertainty over the production function for schooling could instead be uncertainty over the market returns to schooling, as in Nguyen (2008). However, students in our sample have a good understanding of what the returns to different types of schooling are (see Appendix 1). We also designed the DVD so that it did not provide students with direct information about returns to different levels of education.

${ }^{21}$ While the program was designed to provide financial aid information, there is an aspect of motivation and inspiration inherent in the messages provided by the "role models" in the DVD. We cannot separate out the importance of providing information about financial aid from the importance of a "role model" effect. However, we show that both parents and students learned new information from the DVD, suggesting that any motivation effect cannot account for all of the impact on outcomes.
} 
responds by reducing effort, which we measure using school absenteeism, school grades and enrollment in college-preparatory high schools.

In any model where imperfect information about the human capital investment process plays a role in determining optimal investments, predictions about how students of different abilities will respond to learning new information about this process are ambiguous. If we assume that higher ability students $(H>L)$ earn higher returns in the labor market $\left(\beta_{H}>\beta_{L}\right)$, then even with imperfect information about $A *$, $e_{H}^{*}>e_{L} *$ given the same set of beliefs over $A_{i}$, or as long as $\underline{A}_{H}>\underline{A}_{L}$. If beliefs of both high and low ability students adjust in the same way to the new information, then effort choices should change in the same way for both. Alternatively, two students with the same market returns to schooling may respond differently to the DVD if they hold different priors over $A_{i}$ : a student who is initially more optimistic about how much effort translates into higher levels of education should respond less to the new information than a student who is more pessimistic about this mapping. Although we cannot measure student priors over the mapping from effort to schooling, in our empirical work we do investigate which students are marginal by examining responses across students of different observed ability, measured by baseline grades.

The simple model may be extended to incorporate parents. Suppose students consider the entire flow of future returns to schooling in their expected utility maximization, suppose adolescents (agents) are more myopic (have higher discount rates) than parents, and suppose that parents (principals) also have uncertain information about the production function for higher education. This last point is not hard to imagine: in the Chilean setting, many parents have not even completed high school. In such a principalagent setting even if students update beliefs about after watching "Abre la Caja", they may discount future returns too heavily to improve effort. Parental learning about $A^{*}$ should therefore have a larger impact on student effort, as long as children can be appropriately incentivized. This larger impact of parental learning is something we investigate in our analysis.

As a final point, note that if schooling depends on student effort and complementary inputs (e.g. as in De Fraja, Oliveira and Zanchi 2010), providing information about financial aid for higher education may have small effects on some measures of effort. Suppose that we measure effort by school grades, and that there are strong complementarities in the production of higher grades: for example, both students and teachers must work harder to produce higher grades. Then, changing beliefs about the expected returns to effort by getting students to watch "Abre la Caja" may be insufficient to "produce" higher grades because the expected marginal product of additional student effort is zero as long as teacher effort remains fixed. 


\section{Empirical framework}

i) Intent to Treat (ITT) effects of exposure to "Abre la Caja" and heterogeneous effects by ability

In the first part of our analysis, we examine whether providing information at all had effects on information sets, expectations and behavior and whether these effects vary for students of different observed ability ( $7^{\text {th }}$ Grade score). The average effect of being exposed to financial aid information in the DVD on each outcome $Y_{i j}$ for the individual $i$ in the school $j$ is given by the estimate of $\beta$ in:

$$
Y_{i j}=\alpha+\beta^{*} T_{i j}+\varepsilon_{i j}
$$

where $T_{i j}$ is an indicator that takes the value of 1 if the individual received any exposure to the financial aid information and $\varepsilon_{i j}$ is an idiosyncratic error term. Fixed effects for five strata of 2007 school SIMCE score are included. Since assignment to treatment is randomized across schools, standard errors are clustered at the school-level.

To explore the existence of heterogeneous treatment effects by observed ability, students are classified as "high ability" if their $7^{\text {th }}$ grade score is between 60 and 70, "medium ability" if the score is between 50 and 60 , and "low ability" if their $7^{\text {th }}$ grade score is less than 50 . We estimate the following equation:

$$
Y_{i j}=\alpha+\beta_{1} * \operatorname{high}_{i j} * T_{i j}+\beta_{2} * \operatorname{medium}_{i j} * T_{i j}+\beta_{3} * \operatorname{low}_{i j} * T_{i j}+\theta_{1} * \operatorname{high}_{i j}+\theta_{2} * \text { medium }_{i j}+\mu_{i j}
$$

where $\beta_{1}, \beta_{2}$ and $\beta_{3}$ represent the average treatment effects of being exposed to the DVD for each of the high, medium and low observed ability students. We are interested in the pattern of the interaction coefficients estimated in this regression to learn more about which students are marginal in this information intervention.

\section{ii) Comparing the impact of Student and Family treatments}

In the second part of our analysis, we test for whether the standardized financial aid information in "Abre la Caja" provided to the student at school has different effects compared to when information is provided to the family. To estimate the ITT of each treatment separately, we estimate the following regression for each outcome at follow-up, $Y_{i j}$ :

$$
Y_{i j}=\delta+\lambda_{A} * A_{i j}+\lambda_{B} * B_{i j}+v_{i j}
$$

where $A_{i j}$ is an indicator for whether student $i$ in school $j$ receives the Student treatment, where $A_{i j}=\{0$; 
1\}. Similarly, $B_{i j}$ indicates the Family treatment, where $B_{i j}=\{0 ; 1\} . v_{i j}$ is a person-specific error term. This regression also includes fixed effects for five strata of 2007 school SIMCE score and standard errors are clustered at the school level. The coefficients $\lambda_{A}$ and $\lambda_{B}$ are interpreted as the ITT of being shown the DVD at school for all students in the Student treatment $\left(\lambda_{A}\right)$ or of being given the DVD to take home, for students in the Family treatment $\left(\lambda_{B}\right)$. These unbiased estimates inform us about what to expect if each program was implemented as designed. We test for whether $\lambda_{A}$ and $\lambda_{B}$ are significantly different from zero, jointly and separately. Given the design of the experiment, we have sufficient power to detect whether the assignment to the Family treatment has a larger than 0.15 standard deviation impact on absenteeism outcomes, relative to Student treatment effects.

Our experimental design resulted in differential compliance rates with actually watching the DVD across groups. In the Student treatment, all students were exposed to the program in class, so our estimate of $\lambda_{A}$ is an unbiased estimate of the average effect of watching the DVD for all students and is also the treatment effect on the treated (TOT). In contrast, $60 \%$ of students assigned to the Family treatment reported watching the DVD at home and these selected students are different on observables from those who choose not to watch the program. Differential compliance across Student and Family treatments makes it difficult to draw conclusions about the relative effect size of actually watching the DVD, alone or with family, using only the ITT estimates. ${ }^{22}$

The average value of outcomes for students in the Family treatment is a weighted average of the effect on students who watch the DVD in this group and those who do not watch the DVD. $\lambda_{B}$ will underestimate the effect of actually watching the DVD at home as long as spillovers from DVD watchers to nonwatchers are zero or small. ${ }^{23}$ This implies that even if we estimate $\lambda_{A} \geq \lambda_{B}$ from (3), watching the DVD at home could still have a larger impact than watching at school, among the set of students who would choose to watch the DVD.

To estimate the impact of actually watching the DVD on compliers in the Family group, we specify the treatment as "watching the DVD at home" and instrument this with assignment to Family treatment. Without additional covariates, this scales up the $I T T^{B}$ by $1 / 0.6$. Since we show evidence of heterogeneity

\footnotetext{
${ }^{22}$ We will show it is plausible to assume that only the parents in the Family treatment were exposed to the DVD, and therefore the relevant heterogeneity to consider is between students in the Student and Family treatment. Furthermore, most students that watched the DVD watched it with their parents, most parents that watched it reported watching with the family, and these reports coincide in most cases. Parent heterogeneity could be important in interpreting the LATE for the Family treatment group, but is not relevant for the comparison we are interested in, in this section.

${ }^{23}$ It is possible, although we think unlikely, that there are negative spillovers from DVD watchers to DVD nonwatchers in the Family treatment.
} 
in treatment effects by baseline observed ability, it is clear that this IV estimate does not identify the ATE of watching the DVD at home, but rather identifies the average effect among those students who choose to watch the DVD at home. These compliers are, on average, of higher baseline ability than the average student. Intuitively, the IV reweights the $I T T^{B}$ to represent the effect among compliers i.e. among higher ability students (Angrist and Krueger 1999). Comparing the IV estimates of the effect of watching the DVD to our estimate of $\lambda_{A}$ is therefore the incorrect comparison to make in the presence of heterogeneous effects. We approach the comparison problem in a different way: by using non-experimental methods to reweight students in the Student group and isolate those who are most like the compliers in the Family treatment.

To be as transparent as possible in creating this group of complier-like observations non-experimentally, we reweight the $A T E$ of being assigned to the Student group using inverse probability weights. This reflects the outcomes of students with baseline observable characteristics most like those of compliers in the Family group (Horvitz and Thompson 1952). To create these weights, we estimate a probit model of whether a student in the Family treatment reported watching the DVD at home, controlling for a rich set of baseline variables that affect who watches the DVD and that likely affect outcomes (demographics, grades in school, type of school attended). Then, these estimated coefficients are applied to students in the Student treatment group to create predicted 'synthetic' probabilities of watching the DVD $\left(\hat{p}\left(x_{i}\right)\right)$ under an alternative regime where choice is possible. Randomization to groups ensures that the distribution of covariates has common support across groups. Using these predicted probabilities, we construct inverse probability weights $w t_{i}=\frac{\hat{p}\left(x_{i}\right)}{\left(1-\overline{p\left(x_{i}\right)}\right)}$ for students in the Student group, and assign $w t_{i}=1$ for control group students (since these students have zero probability of watching the DVD by experimental design) and $w t_{i}=1$ for students in the Family group. Students with a high predicted 'synthetic' probability of selecting into DVD watching, based on observables, are weighted up in the regression. ${ }^{24}$ This strategy isolates the treatment effect of watching the DVD in the Student treatment group for the set of students who are observably likely to choose to watch the DVD.

One assumption we must make is that the probit model of selection into watching contains all observables that predict the choice to watch and is correctly specified: if selection into watching the DVD is also a function of unobservables then this reweighting may produce biased estimates. We estimate this probit

\footnotetext{
${ }^{24}$ Inverse Probability Weighting (IPW) is often used in the context of adjusting outcomes for untreated units to create a comparable comparison group for treated units (Horvitz and Thompson 1952; Hirano, Imbens and Ridder 2003; Wooldridge 2001). In this case, we are reweighting outcomes for students who have been treated under a different regime, or, not exposed to the Family treatment at all. We can therefore think of students in the Student treatment as one possible control group for students in the Family treatment.
} 
model with a set of baseline covariates that correctly predict $60 \%$ of DVD choices for the students within the Family treatment, leaving less room for unobservable characteristics to affect these choices.

Combining the IV and reweighting approach, the regression equation becomes:

$$
Y_{i j}=\tilde{\alpha}_{0}+\alpha_{I P W} A_{i j}+\alpha_{I V} D V D \text { at Home } i j+\epsilon_{i j}
$$

Note that we do not want to compare the reweighted estimate of $\alpha_{I P W}$ with $\lambda_{B}$. This is because within the Family treatment group, $\lambda_{B}$ weights all observations (those who watch the DVD and those who did not) equally; while $\alpha_{I V}$ estimates of the effect of watching the DVD at home for students who complied with the treatment. With the results of equation (4) in hand, we can make clearer statements about the relative effects of watching the DVD at school or at home. If $\alpha_{I P W}<\alpha_{I V}$ then watching the DVD at home has a larger average impact on outcomes than watching at school, for students who would choose to watch the DVD if given the option to watch. If, on the other hand, $\alpha_{I P W} \geq \alpha_{I V}$, then watching at home has no larger impact on outcomes than watching at school for this type of student.

\section{Data description}

\section{i. $\quad$ Data Sources}

We use data from our baseline and follow-up surveys of students and parents, as well as administrative data provided by the schools and the Chilean Ministry of Education. ${ }^{25}$ Scores in $7^{\text {th }}$ Grade and $8^{\text {th }}$ Grade attendance data at the individual level were collected directly from the schools. School-level SIMCE scores from 2007 (used to stratify the sample), $8^{\text {th }}$ Grade scores and $9^{\text {th }}$ Grade enrollment at the individual level were provided by the Ministry of Education and matched using unique identification numbers.

\section{ii. $\quad$ Sample characteristics and baseline balance}

Tables 1 and 2 provide summary statistics for our data, separately for students assigned to any information treatment and control groups. Our baseline survey captures responses from 6,233 students. At follow-up, we have survey responses from 5,009 students (80\%) who were present and gave consent at the baseline visit. Importantly, attrition from the baseline sample is the same across treatment and control groups (Table 1), at about 20\%. Parent response rates are higher at baseline (75\%) than at follow-up $(58 \%)$, but these response rates are also balanced across treatment and control schools. The lack of differential attrition across treatment and control groups gives us more confidence in the internal validity

\footnotetext{
${ }^{25}$ We thank the Ministry of Education for the access to this data.
} 
of our results. However, since school absenteeism is one of our main outcomes and levels of absenteeism are high at baseline and at follow-up, we discuss attrition in detail in Appendix C. We show that equal attrition across groups on the day of our survey does not conflict with differential absenteeism (as an outcome) across groups in the month before the survey.

The second panel of Table 1 shows the fraction of our baseline student sample that matched administrative data: we have $8^{\text {th }}$ Grade scores for almost all students present at baseline, and $9^{\text {th }}$ Grade enrollment data for $94 \%$ of students present at baseline. ${ }^{26}$ The match rate with $7^{\text {th }}$ Grade scores and absenteeism data is lower at $88 \%$ and $58 \%$ respectively. All of these variables were collected directly from schools. These lower match rates are explained by some schools not having records to share with us (two schools did not have Grade 7 data), some schools not having daily absenteeism records, some schools not having legible records, as well as inaccuracies in recording of identification numbers. The most important fact to take from these match rates is that they are not significantly different across treatment and control schools. Appendix B Table 1 shows they are also not different between the Student and Family treatment groups.

Table 2 shows means and standard deviations of student-level and school-level variables for each of the treatment and control groups. For most variables, means are computed over the sample of students present at baseline. For the education expectations and financial aid information questions, we further restrict the sample to students present at follow-up (i.e. the analysis sample for these outcomes). Looking at control group means, students are about 14 years old and only $54 \%$ of mothers have completed high school. This latter figure highlights the potential for information asymmetries to affect educational investment choices, since many students not have parents with experience in graduating high school, let alone continuing to post-secondary education. We create three categories of $7^{\text {th }}$ Grade score: $29 \%$ of the control group have a low grade (below 50), 58\% have a medium grade (between 50 and 60) and $13 \%$ have a high grade (60 to 70 ) on a scale of 0 to 70 . We use these grades as a baseline measure of student ability.

Families that send their children to these schools (about $30 \%$ of our schools are private voucher schools and the rest are municipal public schools) are from the two lowest income quintiles in Chilean society. However, these households are urban areas of a middle-income country, so it is not surprising that $89 \%$ of the sample has a working DVD player at home. Most students in the Family treatment could have watched the DVD at home if they had wanted to.

\footnotetext{
${ }^{26}$ The less-than-perfect match rate is explained by errors in the schools reports that are corrected but not yet incorporated by the Ministry of Education in official statistics.
} 
The second panel of Table 2 reports the main student-level outcomes at baseline. A large fraction of students $(77 \%)$ report that they want to study beyond high school. This is much higher than the $12.7 \%$ of young adults aged 18-25, in the lowest two income quintiles, who are actually enrolled or have completed any post-secondary education in 2006 (CASEN, 2006). The students who report wanting to continue with post-secondary studies are split evenly between wanting to continue studies at college (32\%) and at vocational/technical schools (32\%). Most students, at baseline, plan to finance their post-secondary studies with scholarships and family finance and a very low fraction (10\%) of students report that they will use loans (multiple mentions were possible for this question). $41 \%$ report they have no idea how they will finance post-secondary education. Our intervention is designed to address this information gap.

Notice that for many of the survey outcomes, there are fewer student responses than students appearing at follow-up ( $\mathrm{N}=5,009)$. Because the survey was self-reported, students sometimes left items blank. We check for whether item non-response is balanced across groups at baseline and follow-up, in Appendix B Table 3 and find that it is for almost all variables.

Average absenteeism reported at baseline by schools underscores the importance of our focus on absenteeism as a measure of effort in school. Over one third of students report being absent from school at least once in the month before our baseline visit and the average number of days absent for students with absenteeism data (including zero absences) was 2.47 days in June.

We were initially concerned with the quality of school administrative records on attendance, especially since minimum school attendance rates are a requirement for schools to receive the public voucher subsidy. We check the quality of the administrative data by comparing it to our own records of whether or not a student was present on the day of our baseline and follow-up visits. That is, for the sample of students for whom we have matched attendance data, we observe whether they are present or absent in class at the time of our baseline visit and we also observe, from school records, whether these students are marked present or absent by their teachers. The average fraction of misreporting by schools is $7 \%: 7 \%$ of students reported present in school registers are not actually in class when we visit the school. This could be because students arrive at school after the survey implementation occurs, or this difference in reporting could reflect intentional misreporting by schools. Although we cannot distinguish between these two possibilities, it is most relevant for our purposes that the mis-reporting of attendance in school registers is balanced across groups (Appendix B Table 4).

Table 2 also shows the results of balancing tests for outcome and control variables at baseline by treatment group assignment. We regress each variable on controls for group assignment and a constant, and cluster the standard errors at the school level. In the final column of the table, we present the p-value 
of the test for whether the Any Treatment $\left(T_{i j}\right)$ dummy is zero. In Appendix B Table 2 we show the test comparing Student and Family treatments. As one might expect from multiple testing of different outcomes in the same sample, it is possible to reject that the difference in means at baseline is zero in a few cases (DVD ownership, low Grade 7 score and whether the student wants to study in a vocational school); however, the Bonferroni test for joint significance of the coefficient on $T_{i j}$ across these balancing regressions cannot reject the null that all coefficients are equal to zero, or that the differences between Student and Family group means are jointly equal to zero. This gives us more confidence that treatment and control groups are the same across a range of observable characteristics at baseline.

\section{6. $\underline{\text { Results }}$}

\section{i. $\quad$ Effects of exposure to "Abre la Caja" on expectations, effort at follow-up and school choice}

Table 3 shows the effects of the intervention on reports of financial aid that students plan to use and student knowledge of information provided in the DVD, three months after the initial survey. We present two specifications for each outcome variable, the first from equation (1) where we are interested in the main effect of exposure and the second from equation (2) where we explore how this exposure effect varies with student observed ability at baseline. All regressions control for SIMCE stratum fixed effects and regressions of equation (2) also include an indicator for whether baseline grades are missing. Sample size varies when students have missing information on the baseline value of the dependent variable.

Exposure to "Abre la Caja" increases the fraction of students reporting that they will finance education with a government loan by 4.6 percentage points (column (3)), and decreases the fraction that do not know how to finance education by 4.2 percentage points (column (7)). This is a large effect: knowledge of loan opportunities increases by almost $50 \%$, and "ignorance" falls by $10 \%$. Interestingly, there is no effect of exposure on reports of using family finance: this is not something that the DVD provided any information on. In column (9), the dependent variable is the number of correct responses to five financial aid questions with multiple choice answers that were asked in the follow-up survey. ${ }^{27}$ We see that treated students score 0.068 points more on the test of information provided in the DVD, which is a $5.5 \%$ improvement relative to the control group mean.).

Even though we do not have the power to detect small differences in effects by student ability, the pattern of coefficient sizes on the interaction terms in Table 3 provides suggestive evidence of heterogeneity in

\footnotetext{
${ }^{27}$ The questions are: 1) How many students do you think state grants or loans to continue studying, 2) what is the minimum PSU score you need for college scholarships, 3) what is the minimum grade you need to apply to a TP or professional scholarship, 4) is the PSU free for municipal or publicly subsidized school students, 5) how do government scholarships work?
} 
impacts by students' $7^{\text {th }}$ Grade scores. A higher fraction of high scoring students (9.4 percentage points) report wanting to use scholarships for finance and these students also seem to drive the effects for increased reporting of loan finance (7.7 percentage points) and the decrease in not knowing how to finance post-secondary school (-7.6 percentage points). Column (10) also indicates that the higher ability students are the ones who remember more information provided in the DVD. These patterns suggest that the marginal students for this information intervention were students with higher initial ability.

Although there are large impacts on information sets and financial aid plans in Table 3, we do not find large average effects of being assigned to an information treatment on whether students plan to study after school at all or on the type of study (Table 4, odd-numbered columns). Given that three quarters of students report wanting to continue with further studies at baseline, it is not surprising that "Abre le Caja" did not raise (or lower) overall educational expectations of any post-secondary education by a significant amount. The results do, however, suggest that within ability group, the new information may have shifted the types of schooling desired. Columns (4) and (6) show that students with higher grades are 7 percentage points more likely to report they will study at college compared to students with low grades, and students with low grades are 8 percentage points more likely to report they will study at a vocational training school. This makes sense, given the grade and PSU cut-offs for financial aid eligibility are lower for attending a vocational school than for attending college.

Note that even though overall educational expectations do not increase, new information about financial aid opportunities could still affect student behavior. Consider the set of students in our sample who report that they will continue with their studies. This fraction was more than five times larger than the actual fraction of students from similar backgrounds who are currently enrolled in post-secondary education. This suggests a slippage between Grade 8 expectations and Grade 12 outcomes. Part of what our DVD emphasized was the importance of current schooling investment decisions -- putting in effort now -- for opening up opportunities four years later. Therefore, we could observe higher effort in school among students who already wanted to continue with their studies (but didn't think it was possible) as a result of learning about the education production function. ${ }^{28}$ In the context of our simple model in section 2, we might observe effort responses among students who were particularly pessimistic about their chances of getting higher education at any effort level.

In Table 5 we present the first results that some, but not all, behaviors do change. In the first four columns we present results for school-reported absenteeism, and in the last columns we show the effect on Grade 8 grades and $9^{\text {th }}$ Grade enrollment. We have two measures of school-reported behavior that capture effort

${ }^{28}$ Jacob and Wilder (2010) show that in the US context, some fraction of the mismatch between early education expectations and eventual outcomes is resolved as students "learn" more about their abilities over time. 
in school: whether the student was absent from school in September at all and the number of days the student missed school in September, where no absences are coded as zeros. ${ }^{29}$ Measuring absenteeism in September 2009, a few weeks before we visit the school for the follow-up survey, reassures us that schools were not manipulating attendance records in anticipation of our visit, as they did not know at the time that we would request records for the entire year.

For students assigned to any exposure to the information treatment, absenteeism prevalence falls by a significant 8.8 percentage points on average. This is a $14 \%$ reduction, relative to the control group mean at follow-up. Looking at the pattern of coefficients on the interactions with baseline grades in column (2), this reduction in prevalence is being driven by students with medium and high scores. And, although not quite significant at conventional levels, total absenteeism in September appears to fall on average by 0.25 days or 0.8 of a standard deviation (or $10 \%$ of June absenteeism). If this effect was sustained over the course of a 10 month school year, it would translate into an increase in attendance of 2.5 days. This reduction on the intensive margin also appears to be driven by students with medium and high baseline grades.

While these effects on absenteeism seem large, they compare well with other estimates in the development literature that look at the impact of health interventions or of information interventions on absenteeism among school children. For example, Miguel and Kremer (2004) show that in a randomized controlled trial of providing primary school students with deworming medication, school attendance increased by about 30 percent while Bobonis, Miguel and Puri-Sharma (2006) find that a combination of deworming medication and iron supplements reduced absenteeism by about one-fifth (increasing attendance by 5.8 percentage points). More closely related to our work, Nguyen (2008) finds that providing statistical information on returns to education to parents of Grade 3 students in rural Madagascar reduces absenteeism by a much larger magnitude: between one-fifth and one-quarter, or 3.5 percentage points on an overall $15 \%$ absenteeism rate.

The final four columns in Table 5 show the effect of exposure to "Abre la Caja" on Grade 8 final grades and school enrollment in Grade 9. There is no effect of treatment assignment on Grade 8 scores. Since the intervention increased attendance by two and a half days at most, it is not surprising that there is no large effect on learning measured as the year's average grade. However, there is also no effect on where

\footnotetext{
${ }^{29}$ As described in the experimental design section, the intervention was conducted in July-August, and the follow-up survey was in October-November. We collected attendance data at the follow-up, and therefore only have attendance data until mid-November at most, depending on the school visit day. Given the large teacher strike in October and November, the only post-intervention month with complete attendance data is September 2009.
} 
students choose to enroll in the following academic year, 6 months after the intervention. Columns (9) and (10) show there is no effect on the probability of being enrolled in a college-oriented high school. ${ }^{30}$

Overall our estimates of the impact of the exposure to information suggest that exposure to "Abre la Caja" improved student information about financial aid options for post-secondary study in Chile, particularly regarding the use of student loans. Students with higher baseline grades were more likely to expect to use scholarships and loans after the intervention and less likely to not know how to finance their studies. These higher ability students also report more knowledge of financial aid eligibility rules. There is no strong statistical evidence of increases in educational expectations at follow-up, although expectations were high to begin with. However there is a change in the type of studies students with different abilities expect to pursue: high ability students increase their expectation of going to college whereas low ability students increase their expectation of pursuing technical studies. Finally, the treatment group adjusted its inputs in school by reducing absenteeism substantially by $14 \%$ overall, 3 months after baseline. However, exposure to the information did not affect other choice margins that are likely more difficult (and which may require other, complementary inputs) to change: $8^{\text {th }}$ Grade scores and enrollment in high school.

ii. Differences between watching "Abre le Caja" at school vs at home: accounting for heterogeneity

In this section we study whether watching the DVD in class or at home had different impacts on outcomes. We begin by showing that watching at home does have an impact on parent information sets. In Table 6, we present results from the OLS regression (in column 1) of parent scores on the short test of the information about financial aid presented in "Abre la Caja". These test scores are measured at baseline for parents; however, because we sent the DVD home with children at baseline, this first survey for parents really captures the first post-treatment outcomes.

Recall that the parental response rate to the baseline survey was $75 \%$. This response rate was not different across treatment and control groups and so under a standard monotonicity assumption on the process governing non-response for parents, and given that we are analyzing data from a randomized experiment, comparison of outcomes across treatment and control groups provides a valid estimate of the impact of treatment on outcomes reported by parents (Lee, 2009). However, as a check, we compute Heckman selection-corrected regression results for the same parent test score outcomes at baseline in column (2). The exclusion restrictions here are two indicators for whether the school was visited twice or three times

\footnotetext{
${ }^{30}$ We also found no evidence that treatment assignment raised scores on the 2009 SIMCE exam, or on the probability of being enrolled at all in Grade 9.
} 
for survey retrieval; the number of visits was allocated randomly to schools. Results from the first stage selection equation are presented in column (3).

In both sets of regressions, uncorrected and corrected for parental non-response, it is clear that parents in the Family treatment group score significantly higher on tests of the DVD knowledge - about 30\% higher than parents in the control group and the Student treatment. This estimate is not sensitive to the Heckman correction. Interestingly, parents score an overall lower score on these tests of knowledge about financial aid than students do: the mean student score within the control group is 1.23 (see Table 3) while for parents, this mean score is only 0.98 .

Next, we compare effects on student outcomes across each of the Student and Family groups. In order to make these comparisons, two important constraints should be held in mind. First, because of the research design, for most outcomes we only have power to detect differences in effect size between Student and Family treatment of 0.15 standard deviations or larger. Second, as noted already, while all respondents in the Student treatment group were exposed to the information because the DVD was shown in class, only $60 \%$ of students in the Family treatment actually watched the DVD. And, as we might expect, the types of students who were more likely to watch the DVD at home are those with higher baseline grades, among other observables. Since the results of the previous section highlighted heterogeneity in treatment responses by baseline grades, selection into watching the DVD that is related to these baseline grades (as well as high values of other observables) makes it more difficult to interpret any differences between Student and Treatment effects. The intuition is that all effects in the Family treatment are averaged over higher ability students who chose to watch the DVD and lower ability students who did not watch at all, while the effects of the Student treatment are averaged over all students who watched the DVD in class.

We tackle this comparison in several ways in Table 7. For each behavioral outcome there are four sets of regression coefficients. The first are the OLS results from regressions of each outcome on a dummy variable for each treatment group, as equation (3) outlines. Since not everyone watched at home, these ITT estimates may underestimate of the average effect of watching the DVD at all, at home. To deal with this, we instrument for watching the DVD at home, using assignment to the Family treatment as the instrument. Given the heterogeneous effects of information suggested by the prior section, this IV provides an estimate of the LATE for compliers, or the TOT. To isolate a comparable set of complier-type students in the Student treatment group, we implement our reweighting approach and inflate the Student treatment effects to identify what we call the synthetic-TOT. Finally, we combine both the IV and reweighting (RW) approach as in equation (4) to compare the effect sizes for compliers (identified by instrumenting within the Family group) and the complier-types (identified by reweighting the Student 
group observations). It is worth noticing that we are finally comparing individuals who watched the DVD in the Family treatment group with similar individuals in the Student treatment group. Since DVD watchers are generally not the students with lower grades, we are unable to say what this Student-Family treatment effect comparison would look like for lower grade students.

We present results for the main behavioral outcomes in Table 7 (absenteeism, grades and enrollment in a college-preparatory high school) and leave the results for information and educational expectations to Appendix B Table 6. In each regression, no other controls are included and standard errors are robust to heteroscedasticity and clustered at the school-level. The inverse probability weights are created using estimates from a probit regression of whether a student reported watching the DVD at follow-up, or not, for the sample of students in the Family group present at follow-up (see Appendix B Table 5 for these estimates). ${ }^{31}$ Sample sizes differ from prior tables because some students in the Family group have missing data on whether they watched the DVD at all. In the bottom row of each panel, we report the minimum detectable effect size, given our sample size and power, in terms of standard deviations of the outcome variable measured at baseline in the control group. ${ }^{32}$ Note that the main coefficient on "Any Exposure to Abre la Caja" from Table 5 is the average of the OLS coefficients on Student and on Family treatments in Table 7.

Comparing the OLS coefficients in columns (1) and (5) with the reweighted coefficients in columns (2) and (6), it is clear that reweighting increases the estimated coefficient on the Student treatment in all cases. Likewise, the estimated coefficients for the Family treatment increase after instrumenting for watching the DVD at home (columns (3) and (7)). The effects of the treatment for compliers are larger for every outcome variable. In the case of school absenteeism on the extensive and intensive margins: the Student treatment decreases the probability of attendance by 6.6 percentage points (not significant), whereas the Family treatment decreases it by 9.4-17.1 percentage points depending on the specification. When the dependent variable is the number of days absent, the Student treatment is only significant when students similar to the DVD watchers in the Family group are weighted up with the inverse probability weight (Panel A: column (6)). Students in the Family treatment decreased the number of days absent

\footnotetext{
${ }^{31} 60 \%$ of students and $53 \%$ of parents report watching the DVD at all. The mean number of times these children watched the DVD was 1.195 times, the median number of times was once. And, of those 711 students who reported watching the DVD at least once, $65 \%$ of them reported watching at least once with their parents. Younger students, students with higher $7^{\text {th }}$ Grade scores and students in private voucher schools are significantly more likely to report watching the DVD, as intuition might suggest. It is striking that low grade students are 42.1 percentage points less likely to watch the DVD. The probit correctly predicts take-up in $60 \%$ of cases. Estimated values of the predicted probability lie between 0.2 and 0.8 , implying that we do not run into the problem of constructing weights with predicted probabilities close to 0 or 1 (Dinardo, 2002).

${ }^{32}$ These minimum detectable effect sizes are computed after the intervention. Initial power calculations were done using SIMCE scores from 2007 data.
} 
between 0.37 and 0.67 days per month. The joint test of significance for Student and Family treatments can reject zero only for the absenteeism outcomes (Panel A), but not for the Grade 8 grades or $9^{\text {th }}$ Grade enrollment outcomes, reflecting what we found in Table 5 using the combined treatment indicator. ${ }^{33}$

Importantly, in no case where we combine the IV and RW procedures, is it possible to reject the null that the two ways of presenting "Abre la Caja" had equivalent effects on outcomes. We interpret these results, in combination with the results in Table 6, in the following way: even though parents in the Family treatment do learn more about financial aid rules than parents in the Student treatment group, the impact of watching the DVD on behavior is not different across these two treatment groups for the set of higher ability students who are likely to watch the DVD on their own.

\section{Discussion and conclusions}

In many middle- and upper-income countries, access to post-secondary education is highly correlated with socioeconomic status of families. This is certainly the case in Chile, despite massive improvements in general education, the existence of many loan and scholarship programs and the recent expansion of some of these sources of public funds. Eligibility for loans and scholarships depends on a combination of high school grades, scores on a national selection test (PSU) and financial need. However, learning about these eligibility requirements is not easy, given the variety of financial aid programs available and the little experience that many parents have with the higher education sector. For some students, finding out that effort in school matters for later outcomes may occur too late in the school career. Adolescents may find it difficult to understand how behaviors in school now may affect eligibility for such funding sources at the end of high school. And, given initial uncertainty about the production function of higher education, learning how financial aid for higher education works may increase or decrease effort in school.

Our project experimentally manipulates exposure to standardized information about financial aid opportunities and eligibility rules for post-secondary school education during the last year of primary school, the point at which choices regarding effort, schools choice and type of study start to define the student's post-secondary opportunities. We additionally manipulate whether students, or students along with their parents, learn about this new information. Our analysis focuses on showing whether exposure

\footnotetext{
${ }^{33}$ Appendix Table 5 shows the impact of the Family and Student treatments on the financial aid knowledge and expectations. We show that there is no differential impact between these two groups on the fraction of students reporting loan finance or the fraction wanting to study in college or in vocational school. We do find that, after combining the IV and RW procedure, the Family treatment has a significantly larger impact on the fraction of students wanting to use scholarship finance and wanting to study after high school at all, and a larger impact on test scores related to DVD knowledge (all of these differences are only significant at the $10 \%$ level).
} 
to the information changes information sets, educational expectations and effort in school, and for which students; as well as testing whether parental exposure can enhance the size of these effects.

We find strong evidence that exposure to "Abre la Caja" raised information sets, shifted education expectations, affected some, though not all, behaviors in school and we have suggestive evidence that these effects were heterogeneous for students of different baseline ability. Among Grade 8 students in Chile, our intervention raised student knowledge of financial aid sources three months later, with the largest impacts on knowledge of loan finance for post-secondary education. Students at all points in the baseline grade distribution are more likely to report the intended use of loans. The pattern of coefficients suggests that the students with higher baseline grades are more likely to respond to the intervention: they report higher intended use of loan finance and scholarship finance, and less uncertainty about how to finance their post-secondary education. Although watching "Abre la Caja" does not seem to have large impacts on educational expectations (which were initially almost unrealistically high), it appeared to induce some sorting on the desired type of post-secondary studies by students' observed ability: students with higher grades were more likely to want to go to college and those with lower grades were more likely to want to go to vocational schools. The one behavior for which exposure to this new information seems to matter is absenteeism: the program improved effort in school by reducing days of absenteeism by 0.8 standard deviations, equivalent to 2.5 extra days of attendance. Absenteeism prevalence among those treated with information fell by $14 \%$. Again, the pattern of coefficients suggests that students with higher grades drive this effect. The small increase in school attendance did not translate into effects on other behavioral margins, notably 8th Grade scores and $9^{\text {th }}$ Grade enrollment choices.

The second set of findings shows that even though parents directly exposed to the DVD in the Family group retained much more information about financial aid eligibility rules than other parents, the effects of watching "Abre la Caja" in the classroom or at home are statistically indistinguishable from each other. Comparing the two treatment effects is not straightforward because students who watched the DVD in the Family treatment were positively selected on observables. To make the results comparable for a set of complier-type students, we combine an instrumental variables adjustment and a reweighting procedure. Under this alternative specification, we find that for those students for whom the financial aid information seem to be more relevant (i.e. higher ability types), watching the DVD has the same impact on outcomes regardless of whether parents also learn this information or not. Although we are unable to say much about what happens when parents of the low ability types are exposed to this financial aid information, given the pattern of selection into watching the DVD at home, what we learn here is relevant for higher ability students who are arguably the ones at risk of missing out on post-secondary schooling opportunities. 
Overall our results on the effects of imperfect information about the net returns to education fall somewhere between the results for developing and developed countries. They add to the body of evidence suggesting that different types of imperfect information can generate underinvestment in human capital (Nguyen, 2008, Jensen 2010) in developing countries and also highlight the importance of considering how students of different abilities respond to the new information. Yet, we also learn that improving information in Grade 8, even among parents, is not sufficient for changing investments like performance in school, or school choice. This result is much more in line with the developed country literature (e.g. Bettinger, Long, Oreopolous and Sanbonmatsu 2009) and suggests that researchers might need to consider earlier or more intense information interventions, or the role of complementary inputs in making new information relevant for educational outcomes. 


\section{References}

Angrist, J. (1993) “The effects of veterans' benefits on education and earnings", Industrial and Labor Relations Review, July 46(4) pp: 637-52

Angrist. J. and G. Imbens (1994) "Identification and estimation of local average treatment effects", Econometrica, Vol 62. No. 2 pp: 467-476

Angrist, J. and A. Krueger (1999) "Empirical strategies in labor economics", in: O. Ashenfelter and D. Card (ed.), Handbook of Labor Economics, edition 1, volume 3, chapter 23, pages 1277-1366 Elsevier.

Attanasio. O. and K. Kauffman (2009) "Educational choices, subjective expectations and credit constraints", NBER Working Paper No. 15087

Avery, C. and T. Kane (2004) "Student Perceptions of College Opportunities: The Boston COACH Program" in Caroline Hoxby (ed.) College Choices: The Economics of Where to Go, When to Go, and How to Pay for It. Chicago: University of Chicago Press

Berry, J (2009) "Child control in educational decisions: An evaluation of targeted incentives to learn in India”, Mimeo, MIT Department of Economics

Bettinger, E., B. Long, P. Oreopolous and L. Sanbonmatsu (2009) "The Role of Simplification and Information in College Decisions: Results from the H\&R Block FAFSA Experiment", NBER working paper 15361

Bobonis, G., E. Miguel and C. Puri-Sharma (2006) “Anaemia and school participation” Journal of Human Resources Vol 41: 4

Bravo, D., S. Mukhopadhyay and P. Todd (2010) "Effects of school reform on education and labor market performance: Evidence from Chile's universal voucher system", Working paper

Burztyn, L. and L. Coffman (2010) “The Schooling Decision: Family Preferences, Intergenerational Conflict, and Moral Hazard in the Brazilian Favelas", MIT Department of Economics

Chiapa, C. and J. L. Garrido and S. Prina (2010) "The Effect of Social Programs and Exposure to Professionals on the Educational Aspirations of the Poor", Mimeo

De Fraja, G., T. Oliveira and L. Zanchi (2010) "Must try harder: Evaluating the role of effort in educational attainment", Review of Economics and Statistics, August Vol 92 No. 3

Dinardo, John (2002), "Propensity Score Reweighting and Changes in Wage Distributions" Mimeo, University of Michigan

Dinardo, J., J. McCrary and L. Sanbonmatsu (2006) "Constructive proposals for dealing with attrition in surveys: An empirical example", Mimeo

Dominitz, J. and Manski, C (1996) "Eliciting student expectations of the returns to schooling" Journal of Human Resources, Vol. 31: 1, pp. 1-26

Dynarski, S. and Scott-Clayton (2006) "The Cost of Complexity in Federal Student Aid: Lessons from Optimal Tax Theory and Behavioral Economics", National Tax Journal, Vol 59: 2, 319-356 
Dynarski, S. (2002) "The behavioral and distributional implications of aid for college" American Economic Review, May

Dynarski, S. (2003) "Does aid matter? Measuring the effect of student aid on college attendance and completion", American Economic Review, March Vol 93(1)

Fryer, R. (2010) "Financial incentives and student achievement: Evidence from randomized trials" NBER Working Paper 15898

Gallego, F. and A.Hernando (2009) "School Choice in Chile: Looking at the Demand Side" mimeo, Pontifica Universidad Católica de Chile.

Giustinelli, P. (2010) "Uncertain outcomes and child-parent decision making in curriculum choice: What data do we need to tell them apart?" Mimeo, Survey Research Center University of Michigan

Gruber, J. (2001) Risky behavior among youths: An economic analysis. University of Chicago Press

Jacob, B. and T. Wilder (2010) "Educational expectations and attainment", NBER Working Paper 15683

Jensen, R. (2010) “The perceived returns to education and the demand for schooling", Quarterly Journal of Economics, February

Hirano, K., G. Imbens and G. Ridder (2003) "Efficient Estimation of Average Treatment Effects using the Estimated Propensity Score,” Econometrica 71, 1161-1189

Hertz, T., Jayasundera, T., Piraino, P. Selcuk, S. Smith, N. Verashchagina, A. (2007) "The Inheritance of Educational Inequality: International Comparisons and Fifty-Year Trends", The B.E. Journal of Economic Analysis \& Policy (Advances), Vol 7: 2

Horowitz, J. L. and C. Manski. (1998) "Censoring of outcomes and regressors due to survey nonresponse: Identification and estimation using weights and imputations", Journal of Econometrics, Vol $84: 37-58$

Horvitz, D. G. and D. J. Thompson (1952) "A Generalization of Sampling Without Replacement From a Finite Universe", Journal of the American Statistical Association, Vol 47. No. 260 December

Hsieh, C-T. and M. Urquiola (2006) "The effects of generalized school choice on achievement and stratification: Evidence from Chile's voucher program”, Journal of Public Economics, Vol 90: 14771503

Kalenkoski, C. (2007) "Parent-child bargaining, parental transfers, and the post-secondary education decision" Applied Economics, 40: 4, 413-436

Kauffman, K. M. (2008) "Understanding the income gradient in college attendance in Mexico: The role of heterogeneity in expected returns", Stanford Institute for Economic Policy Research Discussion Paper Number 07-040

Kremer, M. and T. Miguel (2004) "Worms: Identifying Impacts on Education and Health in the Presence of Treatment Externalities" Econometrica vol. 72(1), pages 159-217, 01 
Lee, D. (2009) “Training, wages and sample selection: Estimating sharp bounds on treatment effects", Review of Economic Studies, Vol 76, 3:1071-1102

Lundberg, S., Romich, J. and K. Tsang (2009) "Decision-making by children", Review of Economics of the Household Vol 7(1)

Manski, Charles F. (1993) "Adolescent Econometricians: How Do Youth Infer the Returns to Schools?" In Studies of Supply and Demand in Higher Education edited by Charles Clotfelter and Michael Rothschild. Chicago: University of Chicago Press

Manski, C. (2004) “Measuring Expectations” Econometrica 72(5): 1329-1376

Meneses, F., Rolando R., Valenzuela M. and M.Vega, (2010) "Ingreso a la Educación Superior: La Experiencia de la Cohorte de Egreso 2005”. Policy Document, Ministerio de Educación. (http://www.divesup.cl/sies/wp-content/uploads/2010/02/Ingreso-a-la-Educación-Superior3.pdf)

MIDEPLAN (2009) “CASEN: Encuesta de caracterización socioeconómica nacional”, Santiago Chile

Ministerio de Planificación (2006) “Casen 2006. Distribución del Ingreso e Impacto Distributivo del Gasto Social" http://www.mideplan.cl/casen/publicaciones/2006/Resultados_Distribucionl_Ingreso_Casen_2006.pdf

Mizala, A. and M. Urquiola (2007) 'School markets: The impact of information approximating schools' effectiveness" NBER Working Paper 13676

Nguyen, T. (2008) "Information, Role Models and Perceived Returns to Education: Experimental Evidence from Madagascar”, Mimeo, MIT

OECD (2009) "Reviews of National Policies for Education: Tertiary Education in Chile"

Psacharopolous, G. (1985) "Returns to Education: A Further International Update and Implications", Journal of Human Resources, Vol. 20, No. 4: 583-604

Psacharopolous, G. (1994) "Returns to investment in education: A global update", World Development, 22: $1325-43$

Solis, A. (2010) Working paper on effect of loan programs on college enrolment in Chile.

SIMCE, Ministerio de Educación (2008) "Manual de uso de la Base de Datos SIMCE 2007 para $8^{\circ}$ Básico". Ministerio de Educación, Chile.

Turner, S. and J. Bound (2002) "Going to war and going to college: Did World War II and the G.I. Bill increase educational attainment for returning veterans?" Journal of Labor Economics Vol 4 October pp. 784-815

Urquiola, M. and E. Verhoogen (2009) "Class size and sorting in market equilibrium: Theory and evidence”, American Economic Review, Vol 99: 1, pp. 179-215

Wooldridge, J. (2001) Econometric Analysis of Cross section and Panel data. The MIT Press

World Bank (2009) "La Educación Superior en Chile" 
Table 1: Distribution of students across experimental groups and match rates with administrative data

\begin{tabular}{|c|c|c|c|}
\hline & Control (C) & Any Treatment (T) & All \\
\hline \multicolumn{4}{|c|}{ Distribution of sample } \\
\hline $\mathrm{N}$ schools at baseline & 114 & 112 & 226 \\
\hline $\mathrm{N}$ schools at follow-up & 114 & 111 & 225 \\
\hline Retention rate of schools (1-attrition) & 1.00 & 0.99 & 1.00 \\
\hline $\mathrm{N}$ students on class roster & 3,902 & 3,794 & 7,696 \\
\hline $\mathrm{N}$ students present at baseline & 3,179 & 3,054 & 6,233 \\
\hline Attendance rate at baseline & 0.81 & 0.80 & 0.81 \\
\hline $\mathrm{N}$ students present at follow-up (Analysis sample) & 2,560 & 2,449 & 5,009 \\
\hline Retention rate of baseline student sample (1-attrition) & 0.81 & 0.80 & 0.80 \\
\hline Response rate of parents at baseline & 0.75 & 0.75 & 0.75 \\
\hline Response rate of parents at follow-up & 0.58 & 0.57 & 0.58 \\
\hline \multicolumn{4}{|c|}{ Match rates with administrative data } \\
\hline N students with matched June absenteeism data & 1,992 & 1,608 & 3,600 \\
\hline Frac. of baseline students with matched June absenteeism data & 0.63 & 0.53 & 0.58 \\
\hline N students with matched September absenteeism data & 1,998 & 1,617 & 3,615 \\
\hline Frac. of baseline students with matched September absenteeism data & 0.63 & 0.53 & 0.58 \\
\hline N students with matched Grade 7 scores data & 2,822 & 2,670 & 5,492 \\
\hline Frac. of baseline students with matched grade 7 scores & 0.89 & 0.87 & 0.88 \\
\hline $\mathrm{N}$ students with matched Grade 8 scores & 3,145 & 3,036 & 6,181 \\
\hline Frac. of baseline students with matched grade 8 scores & 0.99 & 0.99 & 0.99 \\
\hline N students with matched Grade 9 enrollment data & 2,982 & 2,878 & 5,860 \\
\hline Frac. of baseline students with matched Grade 9 enrollment data & 0.94 & 0.94 & 0.94 \\
\hline
\end{tabular}

Table provides summary statistics for schools, students and parents participating in the project. Students present at baseline are those who show-up at school on the day of our visit and responded to the survey. Match rate with administrative data is the fraction of students present at our survey at baseline who we can match with administrative data based on national identification number. Differences in match rates not statistically significant. 
Table 3: Effects of exposure to "Abre la Caja" on financial aid knowledge and expectations at follow-up: OLS

\begin{tabular}{|c|c|c|c|c|c|c|c|c|c|c|}
\hline & \multicolumn{2}{|c|}{$\underline{\text { Scholarship finance }}$} & \multicolumn{2}{|c|}{ Loan finance } & \multicolumn{2}{|c|}{ Family finance } & \multicolumn{2}{|c|}{$\frac{\text { DNK how to }}{\text { finance }}$} & \multicolumn{2}{|c|}{$\begin{array}{l}\text { Score on eligibility } \\
\underline{\text { rules test ( }=0 \text { to } 5)}\end{array}$} \\
\hline & (1) & $(2)$ & (3) & (4) & (5) & (6) & $(7)$ & (8) & (9) & $(10)$ \\
\hline Any exposure to "Abre la Caja" & $\begin{array}{c}0.026 \\
(0.020)\end{array}$ & & $\begin{array}{c}0.046 * * * \\
(0.012)\end{array}$ & & $\begin{array}{c}0.009 \\
(0.016)\end{array}$ & & $\begin{array}{c}-0.042^{* *} \\
(0.019)\end{array}$ & & $\begin{array}{c}0.068 * * \\
(0.034)\end{array}$ & \\
\hline Any exposure*Low grade & & $\begin{array}{c}0.032 \\
(0.028)\end{array}$ & & $\begin{array}{c}0.0418^{* *} \\
(0.020)\end{array}$ & & $\begin{array}{c}0.040 \\
(0.030)\end{array}$ & & $\begin{array}{l}-0.050 \\
(0.035)\end{array}$ & & $\begin{array}{c}0.071 \\
(0.050)\end{array}$ \\
\hline Any exposure*High grade & & $\begin{array}{c}0.0937 * * \\
(0.044)\end{array}$ & & $\begin{array}{c}0.0773^{* *} \\
(0.034)\end{array}$ & & $\begin{array}{l}-0.015 \\
(0.037)\end{array}$ & & $\begin{array}{c}-0.0761 * \\
(0.040)\end{array}$ & & $\begin{array}{c}0.092 \\
(0.086)\end{array}$ \\
\hline Medium grade & & $\begin{array}{c}0.1189 * * * \\
(0.024)\end{array}$ & & $\begin{array}{c}0.021 \\
(0.015)\end{array}$ & & $\begin{array}{l}-0.002 \\
(0.026)\end{array}$ & & $\begin{array}{c}-0.0597 * \\
(0.032)\end{array}$ & & $\begin{array}{c}0.065 \\
(0.044)\end{array}$ \\
\hline High grade & & $\begin{array}{c}0.3908 * * * \\
(0.038)\end{array}$ & & $\begin{array}{c}0.0808 * * * \\
(0.025)\end{array}$ & & $\begin{array}{l}-0.010 \\
(0.035)\end{array}$ & & $\begin{array}{c}-0.2106^{* * *} \\
(0.038)\end{array}$ & & $\begin{array}{c}0.101 \\
(0.066)\end{array}$ \\
\hline Control group mean & 0.32 & 0.32 & 0.10 & 0.10 & 0.29 & 0.29 & 0.46 & 0.46 & 1.23 & 1.23 \\
\hline Pval: Any*Low=Any*Med & & 0.73 & & 1.00 & & 0.29 & & 0.78 & & 0.94 \\
\hline Pval: Any*Med=Any*High & & 0.12 & & 0.35 & & 0.67 & & 0.39 & & 0.78 \\
\hline Pval: Any*High=Any*Low & & 0.24 & & 0.37 & & 0.26 & & 0.61 & & 0.83 \\
\hline
\end{tabular}

Table presents OLS coefficients on an indicator for Abre la Caja exposure, and (in even-numbered columns) indicators for whether baseline grades were medium or high and low, medium and high grade interactions with treatment assignment.*** $\mathrm{p}<0.01$, ** $\mathrm{p}<0.05$, * $\mathrm{p}<0.1$. Robust standard errors in parentheses, clustered at the school-level. All regressions contain stratum fixed effects that define the quintile of the SIMCE 2007 score distribution into which each school falls and a missing Grade 7 score indicator. Outcomes in column 1-8 are binary and not mutually exclusive categories; eligibility rules test score ranges from 0 to 5. 
Table 4: Effects of exposure to "Abre la Caja" on student education expectations at follow-up: OLS Do you think you will study:

\begin{tabular}{|c|c|c|c|c|c|c|}
\hline & \multicolumn{2}{|c|}{ After high school? } & \multicolumn{2}{|c|}{ At college? } & \multicolumn{2}{|c|}{$\frac{\text { At a vocational }}{\text { school? }}$} \\
\hline & $(1)$ & $(2)$ & $(3)$ & (4) & $(5)$ & (6) \\
\hline Any exposure to "Abre la Caja" & $\begin{array}{c}0.011 \\
(0.016)\end{array}$ & & $\begin{array}{c}0.022 \\
(0.020)\end{array}$ & & $\begin{array}{c}0.003 \\
(0.020)\end{array}$ & \\
\hline Any exposure*Low grade & & $\begin{array}{c}0.013 \\
(0.028)\end{array}$ & & $\begin{array}{l}-0.026 \\
(0.032)\end{array}$ & & $\begin{array}{c}0.0865 * * \\
(0.035)\end{array}$ \\
\hline Any exposure*Medium grade & & $\begin{array}{c}0.022 \\
(0.020)\end{array}$ & & $\begin{array}{c}0.038 \\
(0.026)\end{array}$ & & $\begin{array}{l}-0.026 \\
(0.026)\end{array}$ \\
\hline Any exposure*High grade & & $\begin{array}{c}0.002 \\
(0.030)\end{array}$ & & $\begin{array}{l}0.0768 * \\
(0.045)\end{array}$ & & $\begin{array}{l}-0.049 \\
(0.045)\end{array}$ \\
\hline Medium grade & & $\begin{array}{c}0.0986^{* * * *} \\
(0.024)\end{array}$ & & $\begin{array}{c}0.0576^{* *} \\
(0.025)\end{array}$ & & $\begin{array}{l}-0.006 \\
(0.029)\end{array}$ \\
\hline High grade & & $\begin{array}{c}0.2400^{* * *} \\
(0.033) \\
\end{array}$ & & $\begin{array}{c}0.2057^{* * *} \\
(0.042) \\
\end{array}$ & & $\begin{array}{c}-0.0836 * * \\
(0.038) \\
\end{array}$ \\
\hline $\mathrm{N}$ & 4,918 & 4,918 & 3,301 & 3,301 & 3,301 & 3,301 \\
\hline $\mathrm{R}^{2}$ & 0.00 & 0.03 & 0.01 & 0.04 & 0.00 & 0.01 \\
\hline Mean outcome for control group & 0.68 & 0.68 & 0.36 & 0.36 & 0.42 & 0.42 \\
\hline Pval: Any*Low=Any*Med & & 0.76 & & 0.08 & & 0.01 \\
\hline Pval: Any*Med=Any*High & & 0.59 & & 0.44 & & 0.66 \\
\hline Pval: Any*High=Any*Low & & 0.80 & & 0.06 & & 0.02 \\
\hline
\end{tabular}

Table presents OLS coefficients on an indicator for Abre la Caja exposure, and (in even-numbered columns) indicators for whether baseline grades were medium or high and low, medium and high grade interactions with treatment assignment.*** $\mathrm{p}<0.01,{ }^{* *} \mathrm{p}<0.05,{ }^{*} \mathrm{p}<0.1$. Robust standard errors in parentheses, clustered at the school-level. All regressions contain stratum fixed effects that define the quintile of the SIMCE 2007 score distribution into which each school falls and a missing Grade 7 score indicator. All outcomes are binary. 
Table 5: Effects of exposure to "Abre la Caja" on student effort and education outcomes at follow-up: OLS Absenteeism (School reports) Test scores and enrollment (MINEDUC data)

Absent in September? Days absent in

Grade 8 scores $\quad$ Enrolled in collegeSeptember $\quad$ Grade 8 scores oriented high school

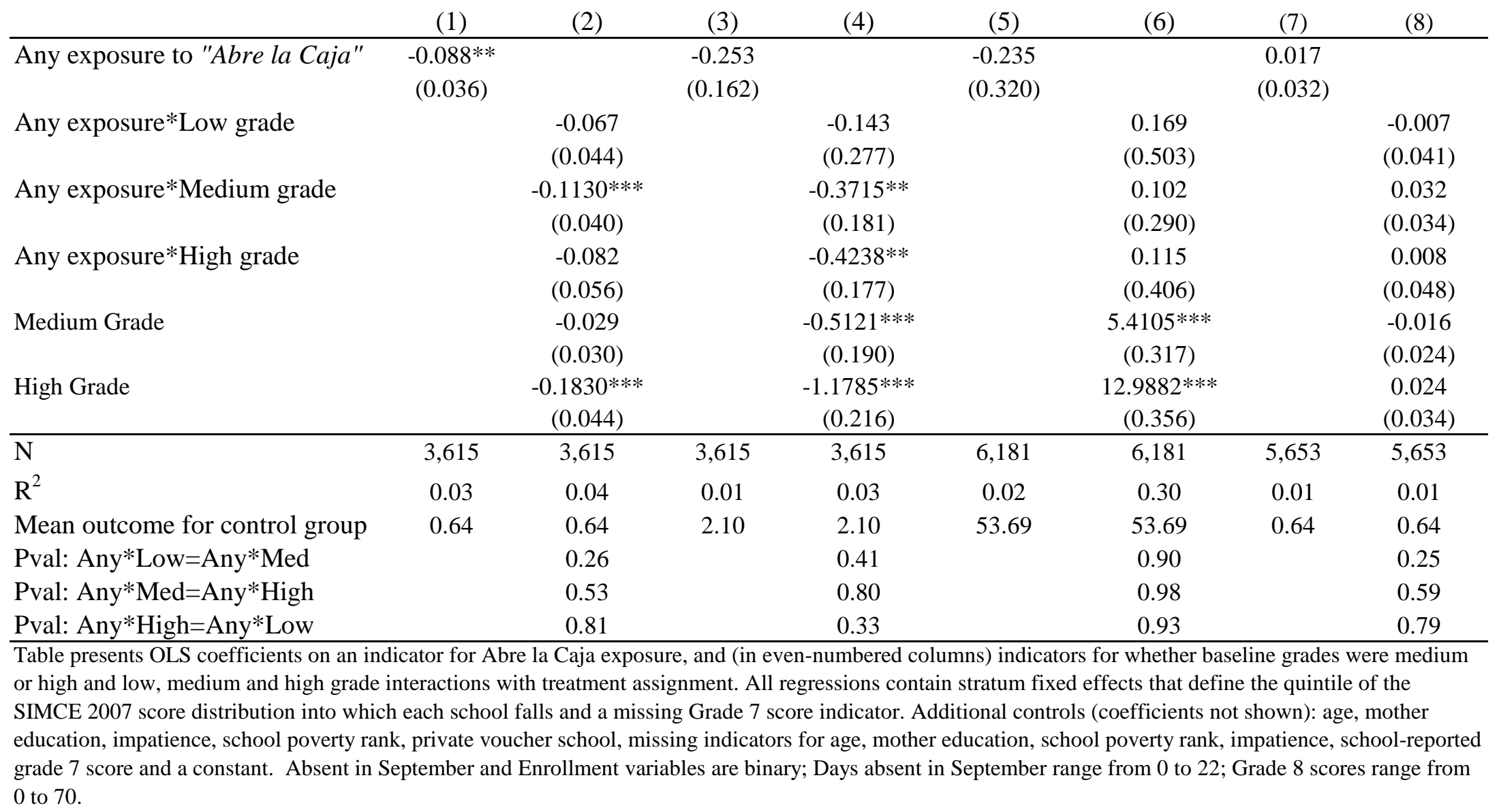


Table 6: Effects of treatment assignment on parental scores of financial aid eligibility rules test $($ Range $=0$ to 5$)$

\begin{tabular}{|c|c|c|c|}
\hline & $\begin{array}{l}\text { OLS: Uncorrected } \\
\text { for parent non- } \\
\text { response } \\
\text { (1) }\end{array}$ & $\begin{array}{l}\text { OLS: Heckman } \\
\text { selection-corrected } \\
\text { for parent non- } \\
\text { response } \\
(2)\end{array}$ & $\begin{array}{l}\text { First stage marginal } \\
\text { effects for the } \\
\text { Heckman selection } \\
\text { (3) }\end{array}$ \\
\hline \multirow[t]{2}{*}{ A: Student treatment } & 0.025 & 0.028 & 0.033 \\
\hline & $(0.034)$ & $(0.025)$ & $(0.039)$ \\
\hline \multirow[t]{2}{*}{ B: Family treatment } & $0.293 * * *$ & $0.290 * * *$ & -0.032 \\
\hline & $(0.034)$ & $(0.033)$ & $(0.037)$ \\
\hline \multirow[t]{2}{*}{ Two repeat visits } & & & $0.283^{* * *}$ \\
\hline & & & $(0.039)$ \\
\hline \multirow{2}{*}{ Three repeat visits } & & & $0.371^{* * *}$ \\
\hline & & & $(0.041)$ \\
\hline$\overline{\mathrm{N}}$ & 4,664 & 6,233 & 6,233 \\
\hline Control group mean & 0.98 & 0.98 & 0.98 \\
\hline Pval for joint test of $A, B$ & 0.00 & 0.00 & 0.00 \\
\hline Pval for test of $A=B$ & 0.00 & 0.00 & 0.00 \\
\hline Mills ratio & & & 0.24 \\
\hline S.e. Mills ratio & & & $(0.18)$ \\
\hline
\end{tabular}

Table shows coefficients from regressions of parent scores on DVD knowledge questions (scale of 0 to 5 ) on assignment indicators. Sample in column (1) includes only parents who who returned surveys to schools at baseline; sample in column (2) is entire baseline sample. Column (3) presents the marginal effects from the first stage of the Heckman selection correction that we implement to deal with parental non-response. Indicators for the number of repeat visits to each school to collect parent surveys are included in the participation equation and excluded from the main equation. ${ }^{* *} \mathrm{p}<0.01,{ }^{* *} \mathrm{p}<0.05,{ }^{*} \mathrm{p}<0.1$. Robust standard errors in parentheses, clustered at the school-level. All regressions contain stratum fixed effects that define the quintile of the SIMCE 2007 score distribution into which each school falls and a missing Grade 7 score indicator. 
Table 7: Effects of treatment assignment on effort in school and educational outcomes: OLS, IV and reweighting

\begin{tabular}{|c|c|c|c|c|c|c|c|c|}
\hline \multirow{4}{*}{ Panel A } & \multicolumn{8}{|c|}{ School reports of absenteeism } \\
\hline & \multicolumn{4}{|c|}{$\underline{\text { Absent in September }}$} & \multicolumn{4}{|c|}{ Num. days absent in September } \\
\hline & OLS & Reweight A & IV B & RW \& IV & OLS & Reweight A & IV B & RW \& IV \\
\hline & (1) & (2) & (3) & (4) & (5) & (6) & (7) & (8) \\
\hline \multirow[t]{2}{*}{ A: Student treatment } & -0.066 & $-0.0885 * *$ & -0.066 & $-0.0885^{* *}$ & -0.220 & $-0.3819 * *$ & -0.220 & $-0.3819 * *$ \\
\hline & $(0.047)$ & $(0.043)$ & $(0.047)$ & $(0.043)$ & $(0.180)$ & $(0.159)$ & $(0.180)$ & $(0.158)$ \\
\hline \multirow[t]{2}{*}{ B: Family treatment } & $-0.0940 *$ & $-0.0940 *$ & $-0.1712 *$ & $-0.1712 *$ & $-0.3663^{*}$ & $-0.3663^{*}$ & $-0.6673 *$ & $-0.6673^{*}$ \\
\hline & $(0.051)$ & $(0.051)$ & $(0.095)$ & $(0.095)$ & $(0.196)$ & $(0.196)$ & $(0.362)$ & $(0.361)$ \\
\hline $\mathrm{N}$ & 2,912 & 2,912 & 2,912 & 2,912 & 2,912 & 2,912 & 2,912 & 2,912 \\
\hline Control group mean & 0.64 & 0.64 & 0.64 & 0.64 & 2.10 & 2.10 & 2.10 & 2.10 \\
\hline Pval for joint test of A, B & 0.13 & 0.06 & 0.14 & 0.06 & 0.15 & 0.04 & 0.15 & 0.03 \\
\hline Pval for test of $A<B$ & 0.31 & 0.46 & 0.13 & 0.18 & 0.25 & 0.47 & 0.10 & 0.20 \\
\hline Minimum detectable diff: (A-B) & 0.15 s.d. & 0.15 s.d. & 0.15 s.d. & 0.15 s.d. & 0.13 s.d. & 0.13 s.d. & 0.13 s.d. & 0.13 s.d. \\
\hline \multirow{3}{*}{$\underline{\text { Panel B }}$} & \multicolumn{4}{|c|}{$\underline{\text { School Grades (MINEDUC data) }}$} & \multicolumn{4}{|c|}{ Enrollment (MINEDUC data) } \\
\hline & \multicolumn{4}{|c|}{ Grades at the end of Grade 8} & \multicolumn{4}{|c|}{ In a college-preparation high school } \\
\hline & OLS & Reweight A & IV B & RW \& IV & OLS & Reweight A & IV B & RW \& IV \\
\hline \multirow[t]{2}{*}{ A: Student treatment } & -0.541 & 0.605 & -0.541 & 0.605 & 0.012 & 0.017 & 0.012 & 0.017 \\
\hline & $(0.357)$ & $(0.448)$ & $(0.357)$ & $(0.447)$ & $(0.045)$ & $(0.047)$ & $(0.045)$ & $(0.047)$ \\
\hline \multirow[t]{2}{*}{ B: Family treatment } & 0.110 & 0.110 & 0.183 & 0.183 & 0.016 & 0.016 & 0.026 & 0.026 \\
\hline & $(0.377)$ & $(0.377)$ & $(0.630)$ & $(0.629)$ & $(0.036)$ & $(0.036)$ & $(0.060)$ & $(0.059)$ \\
\hline $\mathrm{N}$ & 4,969 & 4,969 & 4,969 & 4,969 & 4,633 & 4,633 & 4,633 & 4,633 \\
\hline Control group mean & 53.69 & 53.69 & 53.69 & 53.69 & 0.64 & 0.64 & 0.64 & 0.64 \\
\hline Pval for joint test of $\mathrm{A}, \mathrm{B}$ & 0.24 & 0.40 & 0.24 & 0.40 & 0.91 & 0.89 & 0.90 & 0.89 \\
\hline Pval for test of $A<B$ & 0.07 & 0.17 & 0.12 & 0.27 & 0.47 & 0.49 & 0.41 & 0.44 \\
\hline Minimum detectable diff: (A-B) & 0.11 s.d. & 0.11 s.d. & 0.11 s.d. & 0.11 s.d. & 0.15 s.d. & 0.15 s.d. & 0.15 s.d. & 0.15 s.d. \\
\hline
\end{tabular}

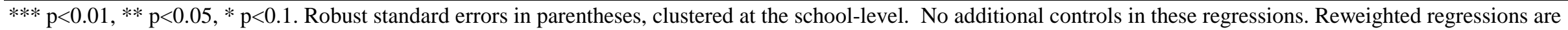

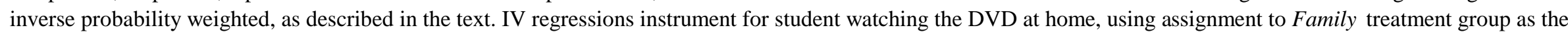

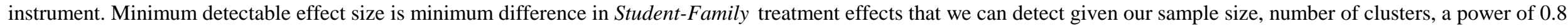
and the intra-cluster correlation in the specific outcome variable at baseline. 


\section{Appendix A: Experimental Design}

\section{Sample selection and randomization}

The project was conducted among schools in the Metropolitan region of Chile. The region includes the city of Santiago and the provinces of Chacabuco, Talagante, Cordillera, Maipo, and Melipilla. We used the list of urban schools present in the 2007 Grade 8 SIMCE database to define our sampling frame. ${ }^{1}$ All schools are required to have $8^{\text {th }}$ Grade students write this exam, so this list represents the universe of schools that existed in Chile in 2007. To focus on children who we might expect to show the largest response to the provision of financial aid information, we selected all schools in the two lowest income groups (as defined by government administrative records) that had at least one Grade 8 class with at least 20 children enrolled in the class. ${ }^{2}$ These criteria left us with over 400 schools, all of which were approached to be part of our experiment. ${ }^{3}$

We hired a call center to contact the schools in our sampling frame and ask them to join our study. A total of 226 schools were reached and agreed to participate. Some fraction of schools declined to participate while others were unable to be reached by phone. We discuss implications of this sample selection on the external validity of our results in Appendix D-External Validity.

We considered the school cluster in the power calculation. The sample allows us to obtain a power of $80 \%$, with a significance level of $5 \%$, a minimum detectable effect size of 0.2 standard deviation, intracluster correlation of 0.27 , cluster size of 30 and an $\mathrm{R}^{2}$ of $0.26-0.29$. The intra-cluster correlation, cluster size and $\mathrm{R}^{2}$ were computed with previous SIMCE data.

\section{Survey data and treatment application}

Before the baseline visit and randomization, we visited each school to obtain signed consent from principals for participation in the project, class lists of all Grade 8 students (larger schools had more Grade 8 classes) as well as Grade 7 scores for these students. ${ }^{4}$ After obtaining these lists from each

\footnotetext{
${ }^{1}$ SIMCE is the national system of evaluation of learning results administered by the Chilean Ministry of Education. The tests evaluate competence in and minimum knowledge of the basic school curriculum. The test it is applied to all students in the country; starting in 2006, the test has been applied yearly to 4th grade students, and every other year to 8 th and 10th graders. We use the $8^{\text {th }}$ grade results from 2007 in this paper for stratification.

${ }^{2}$ Schools are classified into one of five socioeconomic groups using four variables: a) father's years of education, b) mother's years of education, c) monthly income and d) Vulnerability Index (IVE) of the school. The first three are collected as part of the SIMCE parent's questionnaire. The last one is calculated yearly by the "Junta Nacional de Auxilio Escolar y Becas” (JUNAEB). (SIMCE, 2008)

${ }^{3}$ In sample selection, we also approached three schools in the next highest income class, in order to make up our sample size.

${ }^{4}$ Two schools (65 students) were unable to provide us with grades; it was sometimes difficult for school principals to quickly collate this information for us. In addition, some schools provided us with incomplete or illegible grade
} 
school, we grouped schools into five strata by SIMCE 2007 score and randomly assigned schools to one of three groups (group A-Student, B-Family or C-Control) within these strata. Randomization at the school-level avoids the possibility of information spillovers within schools. One Grade 8 class was randomly selected from each school to participate in the study. ${ }^{5}$

The baseline survey and the intervention were conducted in July and August 2009; the follow-up survey in late November and early December 2009. All students present at baseline and follow-up filled in a selfreported survey and were asked to take home parent surveys that were to be returned to school the following week. To incentivize return of the parent survey, we ran a lottery in which students who returned their parent surveys had the chance to win a computer. To address the potential selection problem of the returned parent questionnaire, we randomly assigned (at the school-level) the number of time the enumerators contacted and visited the school to pick up parent questionnaires (one, two or three times). This follows one solution to selected survey non-response suggested in Dinardo, McCrary and Sanbonmatsu (2006).

At the follow-up time, we also collected school records on absenteeism for Grade 8 students for the whole year, up to the date of the follow-up visit. Schools were not expecting us to collect this information, and so it is unlikely that they could have retrospectively tampered with these administrative records.

A nation-wide teacher strike occurred before our follow-up survey. However, by the time we went into the field, all teachers were back at work and we were able to re-contact all schools from the baseline to continue participation at follow-up. Only one school refused to participate in the follow-up, leaving us with data from students in 225 schools.

To complement our survey data, we obtained administrative data from the Ministry of Education on student outcomes at the end of Grade 8 (reported at the school-level), student scores on the 2008 SIMCE, the outcome of Grade 8 (pass/fail/withdraw) and the school in which the student is enrolled in 2009. We match all of our survey data with the administrative data using the national identification number.

\section{Nature of the treatment and randomizing financial aid information}

Students were shown the DVD in class in group A (Student treatment) schools, and students in group B

lists. This means that some students do not have grade 7 scores, even though their school provided us with this information. For these students, we impute a grade 7 score using the class mean grade 7 score and create an indicator variable to capture that this value is imputed. All regressions that control for grade 7 score also control for the grade 7 score imputed indicator.

${ }^{5}$ Questionnaires were printed with the students name and national ID, and the enumerator individually gave them to each students. We therefore expect none, or minimal, manipulation of the students that received the intervention within the school. 
(Family treatment) schools were given a copy of the DVD to take home and watch with their parents. At the end of watching the program at school, a short follow-up questionnaire was also completed by students in group A schools.

Treating the parents separately from children was deemed infeasible for budget reasons. We were not able to visit each household separately. We also chose not to provide students in the Student treatment with their own DVD because it would then be impossible to separately identify the impact of family being exposed to the DVD and the impact of the student watching the DVD more than once (an intensity effect).

Since our sample is based in urban Chile, we expected most students to know that earnings increase with education level and to have a good idea of what this slope is like, both in the aggregate and idiosyncratically. Several small focus groups before baseline confirmed this idea. However, to provide even more evidence on this, we asked variants of two simple questions of two halves of the control group at the end of the baseline survey: ${ }^{6}$

\section{Control group 1}

- What do you think your monthly earnings would be if you were a doctor?

- What do you think your monthly earnings would be if you were a computer programmer?

\section{Control group 2}

- What do you think someone who is a doctor earns each month?

- What do you think someone who is a computer programmer earns each month?

In Appendix A Figure 1, we show three bars that represent the (median of) reported returns to education for the average student (red line) as answered by control group 2, the (median of) reported returns to education for the student themselves (green line) as reported by control group 1, and the actual (median) returns to a technical and a college degree taken from the CASEN (MIDEPLAN, 2008) data. The graph indicates that student expectations of earnings for typical careers with higher and lower levels of education are not far from actual returns, and that there are no systematic differences between representative and idiosyncratic expected earnings.

Students living in urban Chile are very different from students in rural parts of the Dominican Republic.

\footnotetext{
${ }^{6}$ Researchers have tried to elicit returns to education information from students for some time (see Dominitz and Manski, 1997; Avery and Kane (2004), Rouse (2004), Jacob and Wilder (2010)). We piloted methods of asking this information from Grade 8 students in a paper and pencil survey, and found the most sophisticated methods were also the most confusing to students. We then settled on the questions outlined in the text.
} 
As Jensen (2010) explains, students in rural areas of that country are unlikely to be exposed to successful individuals from whom they can infer returns to education. The setting in urban Chile is also different from the situation facing Grade 3 students in rural Madagascar, where Nguyen (2008) shows that less than half of parents have completed primary school. In both of these studies, information about Mincer returns to education did have sizeable effects on effort in school. The information in Appendix A Figure 1 suggests, in contrast, that manipulating information about wages for different levels of education might not have been useful among Chilean students and that any effects that we see from our treatment are unlikely to operate through changes in the expected returns to education.

We defined the intervention around two critical elements that may affect early educational choices of children from poor backgrounds in addition to returns to education information: knowledge about loans and scholarships opportunities and role models. While the program was primarily designed to provide financial aid information, there is an aspect of motivation and inspiration inherent in the messages provided by the "role models" in the DVD. In contrast to what they know about returns to education, our Chilean students are much less likely to have picked up details on how individuals from similar backgrounds managed to pursue higher education (50\% of students in the sample report knowing someone in their family that has studied after high school). Our program, providing a standardized message to students, emphasizes the importance of good high school performanceappn, produced by effort at school, for eligibility and access to financial aid for future studies.

We cannot separate out the importance of providing information about financial aid from the importance of the "role model" effect; however, we interpret exposure to the program as exposure to a message of "You too can do it" (an alternate to the "default behavior" of no further study) that provides students with no direct information about returns to education, and a lot of information about how to improve chances of eligibility for study and how to overcome the hurdle of tuition. ${ }^{7}$ Using test score data on what information was retained from the DVD, we show that both students and parents learned new information. This suggests that any motivation effect cannot account for all of the impact on outcomes.

\footnotetext{
${ }^{7}$ Dynarski and Scott-Clayton (2006) discuss different “default options” that teenagers from poor and rich socioeconomic backgrounds may face.
} 


\section{Appendix A Figure 1}

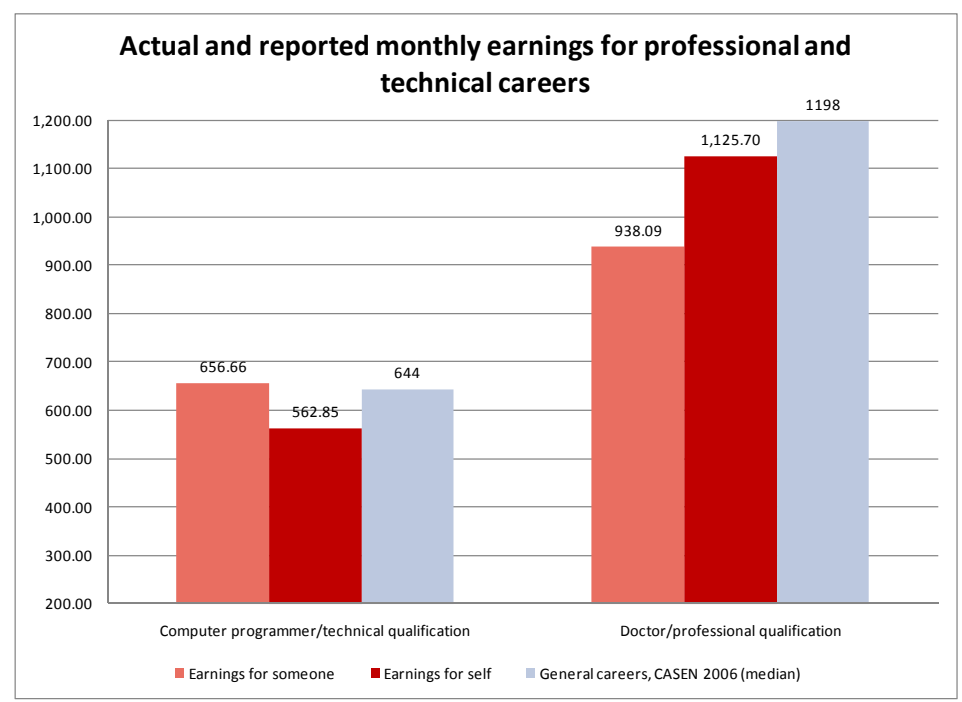

Figure shows median monthly earnings in USD (533 pesos=1 USD in 2009) for different levels of education. Light blue bars represent (weighted) median monthly earnings computed from actual data of adult workers age 30-40 years, who are either technically or professionally trained ("General Careers" from CASEN 2006) and who live in the Metropolitan region of Chile. Red bars are from student reports of what they think they would earn at the age of 30, if they worked as a computer programmer or doctor ("Earnings for self") or what they think someone of age 30 working as a computer programmer (or doctor) could earn ("Earnings for someone”). 
Appendix B Table 1: Distribution of students across Student and Family treatment groups and match rates with administrative data

\begin{tabular}{|c|c|c|}
\hline & $\begin{array}{c}\text { Student Treatment } \\
\text { (A) }\end{array}$ & $\begin{array}{c}\text { Family Treatment } \\
\text { (B) }\end{array}$ \\
\hline \multicolumn{3}{|c|}{ Distribution of sample } \\
\hline N schools at baseline & 56 & 56 \\
\hline $\mathrm{N}$ schools at follow-up & 56 & 55 \\
\hline Retention rate of schools (1-attrition) & 1.00 & 0.98 \\
\hline $\mathrm{N}$ students on class roster & 1,908 & 1,886 \\
\hline $\mathrm{N}$ students present at baseline (main sample) & 1,536 & 1,518 \\
\hline Attendance rate at baseline & 0.81 & 0.80 \\
\hline $\mathrm{N}$ students present at follow-up (main sample) & 1,254 & 1,195 \\
\hline Retention rate of baseline student sample (1-attrition) & 0.82 & 0.79 \\
\hline Response rate of parents at baseline & 0.76 & 0.74 \\
\hline Response rate of parents at follow up & 0.56 & 0.57 \\
\hline \multicolumn{3}{|c|}{ Match rates with administrative data } \\
\hline N students with matched June attendance data & 884 & 724 \\
\hline Frac. of baseline students with matched June attendance data & 0.58 & 0.48 \\
\hline N students with matched September attendance data & 887 & 730 \\
\hline Frac. of baseline students with matched September attendance data & 0.58 & 0.48 \\
\hline $\mathrm{N}$ students with matched Grade 7 scores data & 1321 & 1,349 \\
\hline Frac. of baseline students with matched grade 7 scores & 0.86 & 0.89 \\
\hline $\mathrm{N}$ students with matched Grade 8 scores data & 1,529 & 1,507 \\
\hline Frac. of baseline students with matched Grade 8 scores & 1.00 & 0.99 \\
\hline $\mathrm{N}$ students with matched Grade 9 enrollment data & 1,437 & 1,441 \\
\hline Frac. of baseline students with matched Grade 9 enrollment data & 0.94 & 0.95 \\
\hline
\end{tabular}

Table provides summary statistics for schools, students and parents participating in the project. Students present at baseline are those who show-up at school on the day of our visit and responded to the survey. Match rate with administrative data is the fraction of students present at our survey at baseline who we can match with administrative data based on national identification number. Differences in match rates not statistically significant. 
Appendix B Table 2: Summary statistics and baseline balance tests

\begin{tabular}{|c|c|c|c|c|c|}
\hline & \multicolumn{2}{|c|}{ Student Treatment (A) } & \multicolumn{2}{|c|}{ Family Treatment (B) } & \multirow{3}{*}{$\begin{array}{l}\text { Pvals for } \\
\text { difference in } \\
\text { means } \\
\text { (5) }\end{array}$} \\
\hline & Means & $\mathrm{N}$ & Means & $\mathrm{N}$ & \\
\hline & (1) & (2) & (3) & (4) & \\
\hline \multicolumn{6}{|c|}{ Student-level variables } \\
\hline Age & 14.01 & 1,536 & 13.99 & 1,518 & 0.70 \\
\hline Female & 0.45 & 1,536 & 0.46 & 1,518 & 0.71 \\
\hline Mother completed high school & 0.50 & 1,536 & 0.53 & 1,518 & 0.28 \\
\hline Missing mother education indicator & 0.17 & 1,536 & 0.14 & 1,518 & 0.10 \\
\hline Low grade 7 score & 0.34 & 1,536 & 0.31 & 1,518 & 0.35 \\
\hline Medium grade 7 score & 0.55 & 1,536 & 0.57 & 1,518 & 0.60 \\
\hline High grade 7 score & 0.10 & 1,536 & 0.12 & 1,518 & 0.37 \\
\hline Grade 7 score missing & 0.14 & 1,536 & 0.11 & 1,518 & 0.43 \\
\hline Has a DVD player at home & 0.90 & 1,525 & 0.91 & 1,501 & 0.34 \\
\hline DVD player is working & 0.88 & 1,501 & 0.88 & 1,486 & 0.92 \\
\hline \multicolumn{6}{|c|}{ Student-level outcomes } \\
\hline \multicolumn{6}{|l|}{ 1. Education expectations } \\
\hline Will study beyond high school & 0.75 & 1,484 & 0.77 & 1,435 & 0.44 \\
\hline At college & 0.29 & 1,077 & 0.31 & 1,062 & 0.41 \\
\hline At a vocational school & 0.35 & 1,077 & 0.36 & 1,062 & 0.54 \\
\hline \multicolumn{6}{|l|}{ 2. Financial aid expectations } \\
\hline Pay for studies w/ scholarships & 0.36 & 1,105 & 0.37 & 1,091 & 0.55 \\
\hline Pay for studies w/ loans & 0.10 & 1,105 & 0.11 & 1,091 & 0.66 \\
\hline Pay for studies w/ family resources & 0.42 & 1,105 & 0.38 & 1,091 & 0.14 \\
\hline No idea how to pay for studies & 0.38 & 1,105 & 0.40 & 1,091 & 0.35 \\
\hline \multicolumn{6}{|l|}{ 3. Absenteeism } \\
\hline Has June school absenteeism data & 0.58 & 1,536 & 0.48 & 1,518 & 0.28 \\
\hline Absent at all in June (school) & 0.68 & 884 & 0.62 & 724 & 0.22 \\
\hline Days absent in June (school) & 2.72 & 884 & 2.19 & 724 & 0.32 \\
\hline \multicolumn{6}{|c|}{ School-level variables } \\
\hline Fraction private voucher schools^ ${ }^{\wedge}$ & 0.30 & 56 & 0.38 & 56 & 0.43 \\
\hline School poverty score (Poorest $=80)^{\wedge}$ & 46.90 & 56 & 47.01 & 56 & 0.95 \\
\hline School continues to grades 9-12 & 0.30 & 56 & 0.18 & 56 & 0.12 \\
\hline Stratum of SIMCE scores in $2007 \wedge$ & 3.04 & 56 & 2.98 & 56 & 0.84 \\
\hline Fraction with school attendance data & 0.86 & 56 & 0.73 & 56 & 0.10 \\
\hline
\end{tabular}

Table shows summary statistics for variables collected in our survey or from administrative data $(\sim$ from schools, $\wedge$ from 2007 SIMCE data). Sample for student-level variables and absenteeism variables includes all students present at baseline; sample for student expectations questions is further restricted to analysis sample present at follow-up. SIMCE score is the combined school-averaged math and language scores on the 2007 Grade 8 SIMCE tests. We impute values for control variables missing values using the mean value of the variable over non-missing observations, or a value of 0 for indicator variables. We create a missing indicator variable to flag these imputed observations in regressions. Missing values for outcome variables are not imputed. Results of balance tests are shown in the final column: we implement these tests by regressing the variable of interest on a constant and an indicator for assignment to any treatment. Robust standard errors are clustered at the school level. *** denotes difference significant at $1 \%$ level, ** and 5\% level and * at $10 \%$ level. See Appendix Tables for analysis of balance by treatment arms, and balance in item non-response.

Note: the joint Bonferroni test for differences in student-level means between Student and Control group, Family and Control group, and Student and Family group does not reject 0 . 
Appendix B Table 3: Item non-response for outcome variables from survey questions: Balance across groups at baseline and follow-up, OLS

\begin{tabular}{|c|c|c|c|c|c|c|c|c|c|c|c|c|c|c|}
\hline & \multicolumn{2}{|c|}{$\frac{\text { Want to study after }}{\underline{\text { high school }}}$} & \multicolumn{2}{|c|}{$\frac{\text { Want to study at }}{\text { college }}$} & \multicolumn{2}{|c|}{$\frac{\text { Want to study at }}{\text { vocational school }}$} & \multicolumn{2}{|c|}{$\underline{\text { Scholarship finance }}$} & \multicolumn{2}{|c|}{$\underline{\text { Loan finance }}$} & \multicolumn{2}{|c|}{$\underline{\text { Family finance }}$} & \multicolumn{2}{|c|}{$\underline{\text { No idea how to finance }}$} \\
\hline & Baseline & Follow up & Baseline & Follow up & Baseline & Follow up & Baseline & Follow up & Baseline & Follow up & Baseline & Follow up & Baseline & Follow up \\
\hline \multicolumn{15}{|l|}{ Combined Treatment variable } \\
\hline Any exposure to "Abre le Caja" & $\begin{array}{l}-0.012 * \\
(0.007)\end{array}$ & $\begin{array}{l}-0.003 \\
(0.004)\end{array}$ & $\begin{array}{l}-0.002 \\
(0.016)\end{array}$ & $\begin{array}{l}-0.016 \\
(0.016)\end{array}$ & $\begin{array}{l}-0.002 \\
(0.016)\end{array}$ & $\begin{array}{l}-0.016 \\
(0.016)\end{array}$ & $\begin{array}{c}0.00 \\
(0.015)\end{array}$ & $\begin{array}{l}-0.011 \\
(0.016)\end{array}$ & $\begin{array}{c}0.00 \\
(0.015)\end{array}$ & $\begin{array}{l}-0.011 \\
(0.016)\end{array}$ & $\begin{array}{c}0.00 \\
(0.015)\end{array}$ & $\begin{array}{l}-0.011 \\
(0.016)\end{array}$ & $\begin{array}{c}0.00 \\
(0.015)\end{array}$ & $\begin{array}{l}-0.011 \\
(0.016)\end{array}$ \\
\hline Constant & $\begin{array}{c}0.055^{* * *} \\
(0.005)\end{array}$ & $\begin{array}{c}0.020 * * * \\
(0.003)\end{array}$ & $\begin{array}{c}0.297 * * * \\
(0.011)\end{array}$ & $\begin{array}{c}0.349 * * * \\
(0.011)\end{array}$ & $\begin{array}{c}0.297 * * * \\
(0.011)\end{array}$ & $\begin{array}{c}0.349 * * * \\
(0.011)\end{array}$ & $\begin{array}{c}0.276^{* * *} \\
(0.011)\end{array}$ & $\begin{array}{c}0.332^{* * *} \\
(0.011)\end{array}$ & $\begin{array}{c}0.276^{* * *} \\
(0.011)\end{array}$ & $\begin{array}{c}0.332^{* * *} \\
(0.011)\end{array}$ & $\begin{array}{c}0.276^{* * *} \\
(0.011)\end{array}$ & $\begin{array}{c}0.332^{* * *} \\
(0.011)\end{array}$ & $\begin{array}{c}0.276^{* * *} \\
(0.011)\end{array}$ & $\begin{array}{c}0.332^{* * *} \\
(0.011)\end{array}$ \\
\hline$\overline{\mathrm{N}}$ & 5,009 & 5,009 & 5,009 & 5,009 & 5,009 & 5,009 & 5,009 & 5,009 & 5,009 & 5,009 & 5,009 & 5,009 & 5,009 & 5,009 \\
\hline $\mathrm{R}^{2}$ & 0.00 & 0.00 & 0.00 & 0.00 & 0.00 & 0.00 & 0.00 & 0.00 & 0.00 & 0.00 & 0.00 & 0.00 & 0.00 & 0.00 \\
\hline \multicolumn{15}{|l|}{ Separate Treatment variables } \\
\hline A: Student treatment & $\begin{array}{c}-0.022 * * * \\
(0.007)\end{array}$ & $\begin{array}{l}-0.005 \\
(0.004)\end{array}$ & $\begin{array}{l}-0.002 \\
(0.020)\end{array}$ & $\begin{array}{l}-0.023 \\
(0.020)\end{array}$ & $\begin{array}{c}-0.002 \\
(0.020)\end{array}$ & $\begin{array}{l}-0.023 \\
(0.020)\end{array}$ & $\begin{array}{c}0.003 \\
(0.019)\end{array}$ & $\begin{array}{l}-0.017 \\
(0.020)\end{array}$ & $\begin{array}{c}0.003 \\
(0.019)\end{array}$ & $\begin{array}{l}-0.017 \\
(0.020)\end{array}$ & $\begin{array}{c}0.003 \\
(0.019)\end{array}$ & $\begin{array}{l}-0.017 \\
(0.020)\end{array}$ & $\begin{array}{c}0.003 \\
(0.019)\end{array}$ & $\begin{array}{l}-0.017 \\
(0.020)\end{array}$ \\
\hline B: Family treatment & $\begin{array}{l}-0.002 \\
(0.008)\end{array}$ & $\begin{array}{c}0.000 \\
(0.006)\end{array}$ & $\begin{array}{l}-0.001 \\
(0.019)\end{array}$ & $\begin{array}{l}-0.009 \\
(0.019)\end{array}$ & $\begin{array}{c}-0.001 \\
(0.019)\end{array}$ & $\begin{array}{l}-0.009 \\
(0.019)\end{array}$ & $\begin{array}{l}-0.003 \\
(0.018)\end{array}$ & $\begin{array}{l}-0.005 \\
(0.019)\end{array}$ & $\begin{array}{c}-0.003 \\
(0.018)\end{array}$ & $\begin{array}{l}-0.005 \\
(0.019)\end{array}$ & $\begin{array}{l}-0.003 \\
(0.018)\end{array}$ & $\begin{array}{l}-0.005 \\
(0.019)\end{array}$ & $\begin{array}{l}-0.003 \\
(0.018)\end{array}$ & $\begin{array}{l}-0.005 \\
(0.019)\end{array}$ \\
\hline Constant & $\begin{array}{c}0.055^{* * *} \\
(0.005) \\
\end{array}$ & $\begin{array}{c}0.020 * * * \\
(0.003)\end{array}$ & $\begin{array}{c}0.297 * * * \\
(0.011)\end{array}$ & $\begin{array}{c}0.349 * * * \\
(0.011)\end{array}$ & $\begin{array}{c}0.297^{* * *} \\
(0.011)\end{array}$ & $\begin{array}{c}0.349 * * * \\
(0.011) \\
\end{array}$ & $\begin{array}{c}0.276^{* * *} \\
(0.011)\end{array}$ & $\begin{array}{c}0.332^{* * *} \\
(0.011)\end{array}$ & $\begin{array}{c}0.276^{* * *} \\
(0.011)\end{array}$ & $\begin{array}{c}0.332^{* * *} \\
(0.011)\end{array}$ & $\begin{array}{c}0.276^{* * *} \\
(0.011)\end{array}$ & $\begin{array}{c}0.332 * * * \\
(0.011) \\
\end{array}$ & $\begin{array}{c}0.276^{* * *} \\
(0.011) \\
\end{array}$ & $\begin{array}{c}0.332^{* * *} \\
(0.011)\end{array}$ \\
\hline $\mathrm{N}$ & 5,009 & 5,009 & 5,009 & 5,009 & 5,009 & 5,009 & 5,009 & 5,009 & 5,009 & 5,009 & 5,009 & 5,009 & 5,009 & 5,009 \\
\hline $\mathrm{R}^{2}$ & 0.00 & 0.00 & 0.00 & 0.00 & 0.00 & 0.00 & 0.00 & 0.00 & 0.00 & 0.00 & 0.00 & 0.00 & 0.00 & 0.00 \\
\hline Pval joint test, $A, B=0$ & 0.00 & 0.46 & 0.99 & 0.53 & 0.99 & 0.53 & 0.96 & 0.69 & 0.96 & 0.69 & 0.96 & 0.69 & 0.96 & 0.69 \\
\hline
\end{tabular}

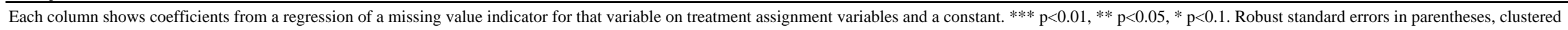
at the school-level. In each regression, sample is restricted to students present at baseline and at follow-up. 


\section{Appendix B Table 4: School misreports of student attendance by group assignment: OLS}

Outcome is school misreporting rate: fraction of students with conflicting attendance data from school records and our survey records

\begin{tabular}{lcc} 
& Baseline & Follow up \\
\hline Combined Treatment variable & 0.008 & 0.002 \\
Any exposure to "Abre le Caja" & $(0.007)$ & $(0.018)$ \\
\hline $\mathrm{N}$ & & 111 \\
$\mathrm{R}^{2}$ & 137 & 0.05 \\
\hline Separate Treatment variables & 0.03 & 0.008 \\
A: Student treatment & & $(0.022)$ \\
B: Family treatment & 0.017 & -0.008 \\
& $(0.011)$ & $(0.022)$ \\
\hline $\mathrm{N}$ & -0.002 & 111 \\
$\mathrm{R}^{2}$ & $(0.006)$ & 0.05 \\
\hline
\end{tabular}

Each column shows coefficients from a regression of the school misreporting rate on treatment group assignment, a constant and SIMCE stratum fixed effects. Column (1) shows results for regressions at baseline, and column (2) for regressions at followup. ${ }^{* *} \mathrm{p}<0.01,{ }^{* *} \mathrm{p}<0.05,{ }^{*} \mathrm{p}<0.1$. Robust standard errors in parentheses, clustered at the school-level. The sample includes all students on the school registers we collected before baseline who also have matched school attendance data. The school misreporting rate is the fraction of students in the sample whose attendance information on the day of our survey visits conflicts with the attendance information from their class registers on the same day. 


\section{Appendix B Table 5: Predicting which students watch the DVD in Family treatment group: Probit marginal effects}

\begin{tabular}{lc} 
& $\underline{\text { Student }}$ \\
& $\underline{\text { watched the }}$ \\
\hline Age & $\underline{\text { DVD }}$ \\
\hline Female & $-0.110^{* *}$ \\
& $(0.05)$ \\
Mom completed HS & 0.100 \\
& $(0.079)$ \\
Mother education missing & 0.003 \\
& $(0.089)$ \\
Medium grade & -0.135 \\
High grade & $(0.122)$ \\
School-reported grade 7 score missing & $0.285^{* * *}$ \\
Impatient & $(0.074)$ \\
Impatient missing & $0.421^{* * *}$ \\
School poverty rank & $(0.147)$ \\
& -0.008 \\
School poverty rank missing & $(0.136)$ \\
& -0.123 \\
& $(0.105)$ \\
& -0.049 \\
& $(0.249)$ \\
& $-0.009^{*}$ \\
& $(0.005)$ \\
& -0.050 \\
& $(0.128)$ \\
& $0.351^{* *}$ \\
& $(0.142)$ \\
\hline
\end{tabular}

Coefficients are estimated marginal effects from a probit regression of whether the student reports watching the DVD or not. *** $\mathrm{p}<0.01,{ }^{* *} \mathrm{p}<0.05$, ${ }^{*} \mathrm{p}<0.1$. Robust standard errors in parentheses, clustered at the school-level. All regressions contain stratum fixed effects that define the quintile of the SIMCE 2007 score distribution into which each school falls and a missing Grade 7 score indicator. Sample is restricted to students in Family treatment group present at baseline and follow-up. 
Appendix B Table 6: Effects of program assignment on expectations and knowledge: IV and reweighting

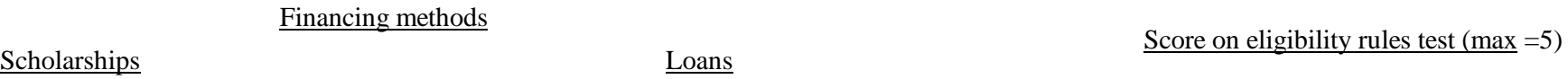

\begin{tabular}{|c|c|c|c|c|c|c|c|c|c|c|c|c|}
\hline \multirow{3}{*}{$\underline{\text { Panel A }}$} & & & \multirow{3}{*}{$\begin{array}{l}\text { OLS } \\
\text { (9) }\end{array}$} & \multirow{3}{*}{$\begin{array}{c}\text { Reweight A } \\
\text { (10) }\end{array}$} & \multirow{3}{*}{$\begin{array}{l}\text { IV B } \\
(11)\end{array}$} & \multirow{3}{*}{$\begin{array}{c}\text { RW \& IV } \\
(12)\end{array}$} \\
\hline & OLS & Reweight A & IV B & RW \& IV & OLS & Reweight A & IV B & RW \& IV & & & & \\
\hline & (1) & (2) & (3) & (4) & (5) & (6) & (7) & (8) & & & & \\
\hline \multirow[t]{2}{*}{ A: Student treatment } & -0.013 & 0.035 & -0.013 & 0.035 & $0.0480 * * *$ & $0.0631^{* * *}$ & $0.0480^{* * *}$ & $0.0631^{* * *}$ & 0.035 & 0.060 & 0.035 & 0.060 \\
\hline & $(0.021)$ & $(0.022)$ & $(0.021)$ & $(0.022)$ & $(0.014)$ & $(0.015)$ & $(0.014)$ & $(0.015)$ & $(0.041)$ & $(0.045)$ & $(0.041)$ & $(0.045)$ \\
\hline \multirow[t]{2}{*}{ B: Family treatment } & $0.0633^{* *}$ & $0.0633^{* *}$ & $0.0968 * *$ & $0.0968^{* *}$ & $0.0430 * * *$ & $0.0430 * * *$ & $0.0657 * * *$ & $0.0657 * * *$ & $0.1049 * *$ & $0.1049 * *$ & $0.1764 * *$ & $0.1764 * *$ \\
\hline & $(0.027)$ & $(0.027)$ & $(0.041)$ & $(0.041)$ & $(0.015)$ & $(0.015)$ & $(0.023)$ & $(0.023)$ & $(0.043)$ & $(0.043)$ & $(0.070)$ & $(0.070)$ \\
\hline$\overline{\mathrm{N}}$ & 3,371 & 3,371 & 3,371 & 3,371 & 3,371 & 3,371 & 3,371 & 3,371 & 5,008 & 5,008 & 5,008 & 5,008 \\
\hline Control group mean & 0.32 & 0.32 & 0.32 & 0.32 & 0.10 & 0.10 & 0.10 & 0.10 & 1.23 & 1.23 & 1.23 & 1.23 \\
\hline Pval for joint test of A, B & 0.03 & 0.04 & 0.02 & 0.04 & 0.00 & 0.00 & 0.00 & 0.00 & 0.05 & 0.04 & 0.04 & 0.03 \\
\hline Pval for test of $\mathrm{A}<\mathrm{B}$ & 0.00 & 0.17 & 0.00 & 0.06 & 0.39 & 0.14 & 0.22 & 0.46 & 0.08 & 0.20 & 0.02 & 0.05 \\
\hline \multirow[t]{2}{*}{ Minimum detectable diff: (A-B) } & 0.11 s.d. & 0.11 s.d. & 0.11 s.d. & 0.11 s.d. & 0.09 s.d. & 0.09 s.d. & 0.09 s.d. & 0.09 s.d. & 0.09 s.d. & 0.09 s.d. & 0.09 s.d. & 0.09 s.d. \\
\hline & \multicolumn{12}{|c|}{ Future education expectations } \\
\hline \multirow[t]{2}{*}{$\underline{\text { Panel B }}$} & \multicolumn{4}{|c|}{$\underline{\text { Study after high school? }}$} & \multicolumn{4}{|c|}{$\underline{\text { Will study technical school }}$} & \multicolumn{4}{|c|}{$\underline{\text { Will study in college }}$} \\
\hline & OLS & Reweight A & IV B & RW \& IV & OLS & Reweight A & IV B & RW \& IV & OLS & Reweight A & IV B & RW \& IV \\
\hline A: Student treatment & $\begin{array}{c}0.016 \\
(0.020)\end{array}$ & $\begin{array}{c}0.0610 * * * \\
(0.022)\end{array}$ & $\begin{array}{c}0.016 \\
(0.020)\end{array}$ & $\begin{array}{c}0.0610^{* * *} \\
(0.022)\end{array}$ & $\begin{array}{c}0.005 \\
(0.026)\end{array}$ & $\begin{array}{l}-0.029 \\
(0.028)\end{array}$ & $\begin{array}{c}0.005 \\
(0.026)\end{array}$ & $\begin{array}{l}-0.029 \\
(0.028)\end{array}$ & $\begin{array}{c}0.005 \\
(0.027)\end{array}$ & $\begin{array}{c}0.049 \\
(0.029)\end{array}$ & $\begin{array}{c}0.005 \\
(0.027)\end{array}$ & $\begin{array}{l}0.0485 * \\
(0.029)\end{array}$ \\
\hline B: Family treatment & $\begin{array}{c}0.007 \\
(0.019)\end{array}$ & $\begin{array}{c}0.007 \\
(0.019)\end{array}$ & $\begin{array}{c}0.011 \\
(0.032)\end{array}$ & $\begin{array}{c}0.011 \\
(0.032)\end{array}$ & $\begin{array}{c}0.003 \\
(0.025)\end{array}$ & $\begin{array}{c}0.003 \\
(0.025)\end{array}$ & $\begin{array}{c}0.004 \\
(0.038)\end{array}$ & $\begin{array}{c}0.004 \\
(0.038)\end{array}$ & $\begin{array}{c}0.037 \\
(0.027)\end{array}$ & $\begin{array}{c}0.037 \\
(0.027)\end{array}$ & $\begin{array}{c}0.056 \\
(0.041)\end{array}$ & $\begin{array}{c}0.056 \\
(0.041)\end{array}$ \\
\hline$\overline{\mathrm{N}}$ & 4,917 & 4,917 & 4,917 & 4,917 & 3,300 & 3,300 & 3,300 & 3,300 & 3,300 & 3,300 & 3,300 & 3,300 \\
\hline Control group mean & 0.68 & 0.68 & 0.68 & 0.68 & 0.42 & 0.42 & 0.42 & 0.42 & 0.36 & 0.36 & 0.36 & 0.36 \\
\hline Pval for joint test of A, B & 0.74 & 0.02 & 0.74 & 0.02 & 0.98 & 0.52 & 0.98 & 0.52 & 0.39 & 0.17 & 0.38 & 0.16 \\
\hline Pval for $A=B$ & 0.69 & 0.03 & 0.88 & 0.13 & 0.95 & 0.30 & 0.99 & 0.40 & 0.32 & 0.73 & 0.22 & 0.86 \\
\hline Pval for test of $\mathrm{A}<\mathrm{B}$ & 0.34 & 0.01 & 0.44 & 0.06 & 0.47 & 0.15 & 0.50 & 0.20 & 0.16 & 0.36 & 0.11 & 0.43 \\
\hline Minimum detectable diff: (A-B) & 0.09 s.d. & 0.09 s.d. & 0.09 s.d. & 0.09 s.d. & 0.09 s.d. & 0.09 s.d. & 0.09 s.d. & 0.09 s.d. & 0.11 s.d. & 0.11 s.d. & 0.11 s.d. & 0.11 s.d. \\
\hline
\end{tabular}

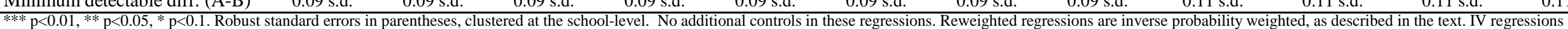

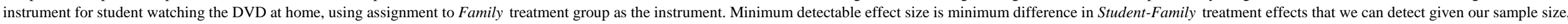

number of clusters, a power of 0.8 and the intra-cluster correlation in the specific outcome variable at baseline. 


\section{Appendix C: Attrition and absenteeism}

As noted in Table 1, we find no evidence of differential attrition across school groups. This lack of differential attrition across treatment and control groups gives us more confidence in the internal validity of our results. However, because we survey students at school, the main source of attrition between baseline and follow-up is absenteeism on the day of our follow-up visit. Given that schoolattendance is one of our measures of child effort, absenteeism at follow-up is tricky to interpret. On the one hand, evidence of non-random absenteeism (attrition) could be taken as evidence that program assignment affected behavior, since school attendance is one of our measures of effort in school. On the other hand, differential attrition across groups at follow-up could cast doubt on the internal validity of our impact estimates for all other outcomes, as it would in any experimental setting.

Attendance measured on the day of our follow-up survey is unlikely to be a good measure of effort in school, since our visits were pre-arranged with school principals and students might have behaved differently on these days. Anecdotally, our study became known as the "Super 8 " study, since we gave students in all groups a choice of sweets at the end of the baseline survey. Also, the promise to be entered into a lottery for a computer, conditional on returning parent questionnaires, seemed to create additional excitement. To investigate whether attendance is different on our survey date, we use daily attendance data for the control group only and estimate a set of OLS regressions for whether a student is absent from school on a given school day or not, for all school days after the baseline and up to the end of our sample period. The idea here is that if our follow-up survey day is "different" to other school days, then we should find absenteeism is significantly lower on our follow-up day, even among control group students who did not receive any information about financial aid.

Appendix C Table 1 presents the output from these regressions and shows the coefficient on an indicator for whether the school day in question is the follow-up visit day or not. Column (1) is from the regression of absenteeism on follow-up visit day indicator and stratum fixed effects; column (2) additionally controls for student fixed effects, column (3) includes student fixed effects and column (4) combines student and day fixed effects. Columns (5)-(8) repeat the same regressions but also include a control for the number of sweets that were given out in the baseline at each school relative to the number of students in the class, and its interaction with follow-up day. This is to test the "Super- 8 " hypothesis. Standard errors are robust and clustered at the student level, since the observation is a student-school day.

The results clearly show that within the control group, students are 3 percentage points less likely to be absent on a follow-up day, relative to other school days; this rises to 8 percentage points when we include day fixed effects and remains about 7.5 percentage points when both sets of fixed effects are included in column (4). What we learn from this table is that, among control group students, attendance is higher on the follow-up visit day than at other times during the school year.appnx 
Furthermore, columns (5)-(8) provide suggestive evidence that this may have been related to the promise of more sweets on our follow-up visit: the interaction of "Sweets" and "Follow-up Indicator" is negative in all cases, although not always statistically significant.

We conclude that attendance on the day of our follow-up visit is not a good measure of the behavioral response to the intervention. Rather, since we are interested in the sustained behavioral effects of our intervention, we use school-reported absenteeism in the month before the survey as our main outcome variables.

A final point about attrition at baseline is worth noting. Absenteeism of students at baseline (attrition before surveying) may affect the external validity of our results. Although not statistically different across schools the rate of absenteeism on the day that we visited schools at baseline is high, at $20 \%$. The students who are unlikely to be at school on the baseline day are, not surprisingly, the students with the lowest Grade 7 scores (results not shown). This means that our results reflect the behavioral responses of higher ability students exposed to different treatments at baseline. However, since the intervention provides information on how to finance post-secondary studies, these higher ability students in the poorest schools are likely the relevant group for policy. 
Appendix C Table 1: Absenteeism among Control group students on follow-up visit day relative to other school days: OLS

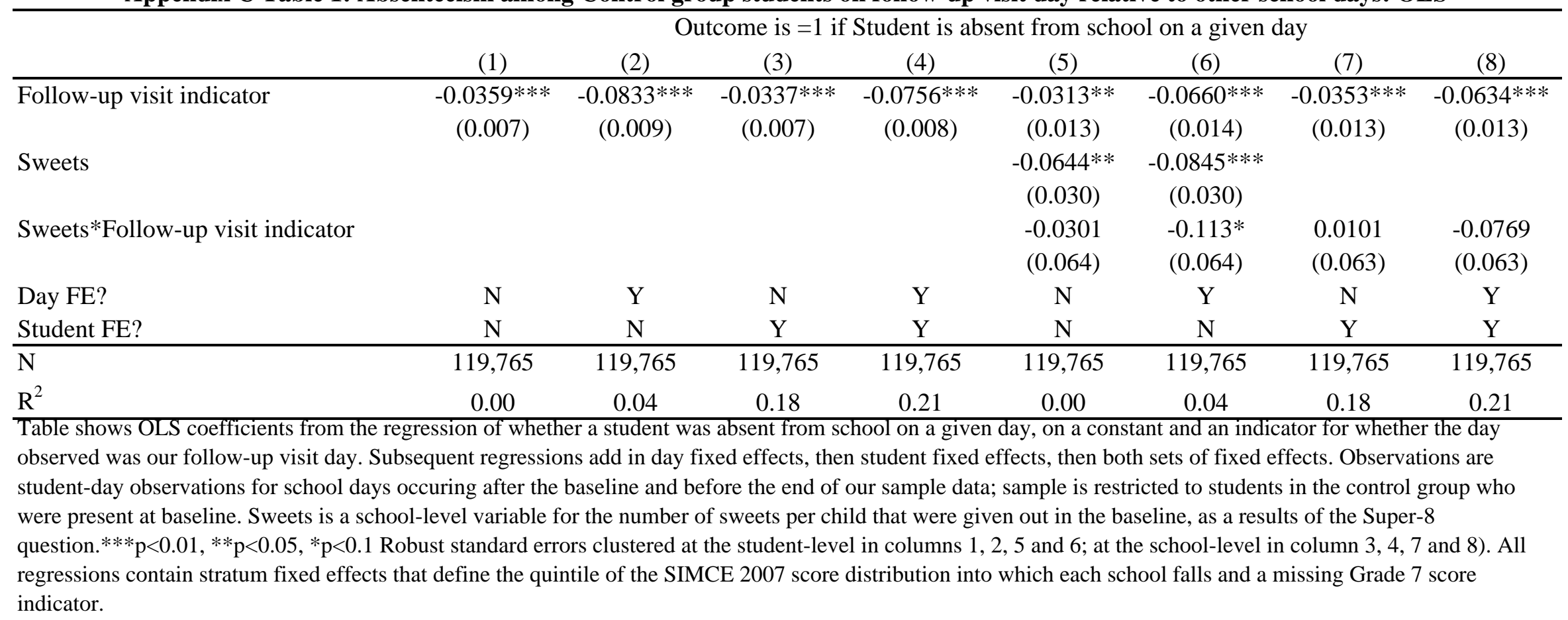




\section{Appendix D: External Validity}

We chose to focus our intervention in the Metropolitan (Metro) region of Chile for practical reasons. Chile is a large country and pursuing a sample of schools that is representative of the entire country's students would have been prohibitively expensive. This sampling choice is one limitation to the external validity of our results. In addition, some schools in the Metro region were unable to be reached by phone to be invited to participate or refused to participate in our study. The omission of these schools from the study also potentially compromises external validity.

We investigate how different participating schools are from schools in the rest of the country in Appendix B Table 1. In column 1, we show means and standard deviations of school-level variables for the 227 experimental schools in the Metro urban region. In column 2, we show means and standard deviations for 264 non-experimental schools in the Metro urban region that are in the same income categories as our sample; these are the refusers and the schools we failed to contact by phone. Column 3 presents the same statistics for 2,979 non-experimental schools in urban regions of the country that are in the same (lowest two) income groups as our sample (i.e. Metro and non-Metro region schools).

Comparing school-level variables across columns, we see that the sample of schools who selected into participation are not significantly different to the non-participating urban schools in the Metro region. This is comforting, because it suggests that the schools that agreed to participate in the study are not selected on observables that may directly affect the expectation and educational investment behaviors that we are interested in. In contrast, our sample does look significantly different to the average nonexperimental school from urban areas across the country in some dimensions. Our sample schools score slightly lower on the overall SIMCE Grade 8 exam in 2007, are significantly more likely to come from the second lowest income class (compared to the lowest class), are larger overall and have larger average Grade 8 classes. They also have a higher fraction of parents owning DVD players. On the other hand, the mean education of mothers and fathers in our sample schools is not significantly different from average parental education in the non-experimental schools from across the country.

Differences in school size and in the socio-economic status (SES) of parents in experimental schools mean that our results may not extrapolate to students in urban areas of the rest of Chile. However, the fraction of all low SES schools with Grade 8 students that are located in Metro urban Chile is $14 \%$ and the fraction of all Grade 8 students in low SES schools that are in Metro urban Chile is 30\%. Therefore, our results are informative for a relatively large fraction of the Chilean student population from low income backgrounds. 


\begin{tabular}{|c|c|c|c|c|c|}
\hline & $\begin{array}{l}\text { Mean (sd) in } \\
\text { experimental } \\
\text { schools }\end{array}$ & $\begin{array}{l}\text { Mean (sd) in } \\
\text { non- } \\
\text { experimental } \\
\text { schools (same } \\
\text { SES, Metro } \\
\text { region) }\end{array}$ & $\begin{array}{l}\text { Mean (sd) in } \\
\text { non- } \\
\text { experimental } \\
\text { schools (same } \\
\text { SES, all } \\
\text { regions) }\end{array}$ & $(1)-(2)$ & $(1)-(3)$ \\
\hline & $(1)$ & $(2)$ & $(3)$ & & \\
\hline SIMCE Grade 8 score in 2007 & 230.02 & 230.95 & 233.91 & -0.94 & $-3.893 * * *$ \\
\hline (math + language) & $(14.20)$ & $(17.52)$ & $(16.12)$ & $(1.46)$ & $(1.13)$ \\
\hline & 227 & 264 & 1,422 & & \\
\hline Lowest SES group indicator & 0.07 & 0.05 & 0.17 & 0.02 & $-0.0994 * * *$ \\
\hline & $(0.26)$ & $(0.22)$ & $(0.38)$ & $(0.02)$ & $(0.03)$ \\
\hline & 227 & 264 & 1,423 & & \\
\hline Second lowest SES group indicator & 0.93 & 0.95 & 0.83 & -0.02 & $0.0994 * * *$ \\
\hline & $(0.26)$ & $(0.22)$ & $(0.38)$ & $(0.02)$ & $(0.03)$ \\
\hline & 227 & 264 & 1,423 & & \\
\hline School poverty score (higher is poort & 46.42 & 46.03 & 48.09 & 0.39 & $-1.670 * *$ \\
\hline & $(9.23)$ & $(9.17)$ & $(10.69)$ & $(0.87)$ & $(0.76)$ \\
\hline & 219 & 234 & 1,361 & & \\
\hline Number grade 8 classes & 1.77 & 1.75 & 1.69 & 0.02 & 0.08 \\
\hline & $(0.85)$ & $(0.86)$ & $(0.80)$ & $(0.08)$ & $(0.06)$ \\
\hline & 227 & 264 & 1,423 & & \\
\hline Number grade 8 kids & 57.63 & 56.38 & 49.31 & 1.26 & $8.320 * * *$ \\
\hline & (33.63) & $(33.82)$ & $(29.43)$ & $(3.05)$ & $(2.15)$ \\
\hline & 227 & 264 & 1,423 & & \\
\hline Grade 8 class size & 31.92 & 31.23 & 28.28 & 0.69 & $3.640 * * *$ \\
\hline & $(6.00)$ & $(8.27)$ & $(8.32)$ & $(0.66)$ & $(0.58)$ \\
\hline & 227 & 264 & 1,423 & & \\
\hline Mother years of education & 8.90 & 9.13 & 8.77 & -0.23 & 0.13 \\
\hline & $(3.42)$ & (3.19) & $(3.46)$ & $(0.32)$ & $(0.26)$ \\
\hline & 198 & 228 & 1,268 & & \\
\hline Father years of education & 8.86 & 9.16 & 8.80 & -0.30 & 0.06 \\
\hline & $(3.46)$ & $(3.48)$ & $(3.64)$ & $(0.34)$ & $(0.28)$ \\
\hline & 195 & 218 & 1,212 & & \\
\hline Households with DVD & 0.77 & 0.76 & 0.69 & 0.01 & $0.0810 * * *$ \\
\hline & $(0.09)$ & $(0.10)$ & $(0.13)$ & $(0.01)$ & $(0.01)$ \\
\hline $\mathrm{N}$ & 227 & 264 & 2,979 & & \\
\hline
\end{tabular}

Column (1) includes only experimental schools. Column (2) includes all non-experimental schools in the lowest 2 income groups in urban areas of the Metropolitan region in Chile. Column (3) includes all non-experimental schools in the lowest 2 income groups in urban areas across the entire country (Metropolitan and other regions). In the final two columns, significant differences represented by ${ }^{* * *} \mathrm{p}<0.01,{ }^{* *} \mathrm{p}<0.05,{ }^{*} \mathrm{p}<0.1$. 